\title{
3D Seismic, Attribute-Assisted, Structural Interpretation for Hydrocarbon Exploration and Production: Southwest Pennsylvania, Central Appalachian Basin
}

Thomas Bradley Donahoe West Virginia University

Follow this and additional works at: https://researchrepository.wvu.edu/etd

\section{Recommended Citation}

Donahoe, Thomas Bradley, "3D Seismic, Attribute-Assisted, Structural Interpretation for Hydrocarbon Exploration and Production: Southwest Pennsylvania, Central Appalachian Basin" (2011). Graduate Theses, Dissertations, and Problem Reports. 4709.

https://researchrepository.wvu.edu/etd/4709

This Thesis is protected by copyright and/or related rights. It has been brought to you by the The Research Repository @ WVU with permission from the rights-holder(s). You are free to use this Thesis in any way that is permitted by the copyright and related rights legislation that applies to your use. For other uses you must obtain permission from the rights-holder(s) directly, unless additional rights are indicated by a Creative Commons license in the record and/ or on the work itself. This Thesis has been accepted for inclusion in WVU Graduate Theses, Dissertations, and Problem Reports collection by an authorized administrator of The Research Repository @ WVU. For more information, please contact researchrepository@mail.wvu.edu. 
3D Seismic, Attribute-Assisted, Structural Interpretation for Hydrocarbon

Exploration and Production:

Southwest Pennsylvania, Central Appalachian Basin.

Thomas Bradley Donahoe

Thesis submitted to the

Eberly College of Arts and Sciences

at West Virginia University

in partial fulfillment of requirements

for the degree of

Master of Science

in

Geology

Dengliang Gao, Ph. D., Chair

Timothy Carr, Ph. D.

Jaime Toro, Ph. D.

Thomas Wilson, Ph. D.

Department of Geology and Geography

Morgantown, West Virginia

2011

Keywords: Appalachian Basin, Unconventional Reservoir, 3D Seismic, Seismic Attributes 


\section{ABSTRACT \\ 3D Seismic, Attribute-Assisted, Structural Interpretation for Hydrocarbon Exploration and \\ Production: Southwest Pennsylvania, Central Appalachian Basin.}

Thomas B. Donahoe

High quality 3D seismic data provides critical information vital to the delineation of structural fabrics and depositional facies, and it is therefore important to the development of ideas associated with structural and facies architecture and growth history of the Appalachian foreland basin. Traditional wiggle trace imagery is limited by its dominant frequency and low signal-to-noise ratio; while conventional seismic attributes, such as instantaneous amplitude, RMS and frequency methods are not effective at defining fracture intensity and orientation and spatial and temporal relations between faults and folds which are crucial in achieving the hydrocarbon exploration objective in the basin. To overcome these limitations advanced seismic attributes such as volumetric curvature, ant tracking and waveform model regression were applied in a multi-attribute analysis to increase the resolution of stratigraphic and structural features including geometries, orientations, boundaries and intensities of faulting, folding and fracturing. Saw-tooth forethrust to backthrust patterns and small-scale, intra-interval, shear zones or detachment faults were observed within the Devonian intervals. From these discontinuities, the primary stress orientation during the Devonian was defined at approximately $105^{\circ}$ to $120^{\circ}$ azimuth which may affect drilling orientations in the hydraulic fracturing process. This effort may be used as an analog for other shale plays as it demonstrates the importance of 3D seismic analysis to understanding the relationship between subsurface structural features and hydrocarbon systems, which are fundamental to the success of future exploration for and production of oil and gas, both conventional and unconventional, in the Appalachian Basin. 


\section{Acknowledgements:}

I would like to express my sincere gratitude to Energy Corporation of America for allowing me to work with their 3D data set, wells logs and other confidential data; to my thesis committee members Dr. Tim Carr, Dr. Jaime Toro and Dr. Tom Wilson for their encouragement and advice; to Dr. Dengliang Gao whom without I surely would have failed. Thank you for your positive encouragement, your invariable interest in the work and your guidance in helping me realize my potential. I would also like to thank my fellow graduate students for assisting in data entry and for discussing geological ideas and principles.

To my family who may not know the encouragement they gave with every question asked and lengthy explanation that accompanied. My loving wife Marissa who put up with me through many long stressful days; your support, kindness, patience and love has helped me achieve what I thought at times could not be done. Finally, I would like to thank God without whom this thesis would not be possible. 


\section{TABLE OF CONTENTS}

Chapter

1

2

3

4

7
Introduction

Geologic Setting

Previous Work

Stratigraphy

Structure

Data and Methodology

Data

Methodology

Results

$2 D$

$3 D$

Interpretations

Structural Fabric Development

Fundamental Interpretations

Structural Interpretations in the Detachment Intervals

Complex Structural Interpretations

Observations and Interpretations of Attribute Calibrations

Hydrocarbon Implications

Conclusions and Future Work

Conclusion

Future Work

Final Thoughts

Bibliography

APPENDIX I

APPENDIX II
51

55

Page Number

1

2

11

19

32

53

59

60 


\section{List of Figures:}

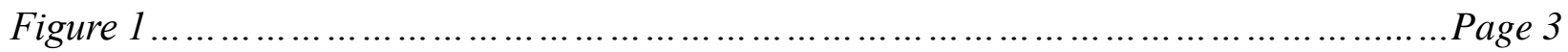

Regional and Local Stratigraphic Columns

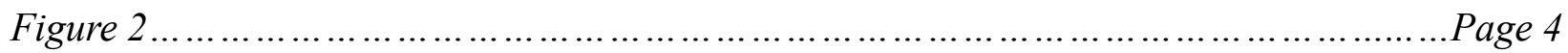

Middle Devonian Stratigraphic Section

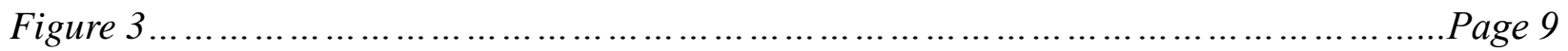

Paleogeography Map at Middle Devonian Time

Figure4.

Regional Basement Structure Map and Cross Section

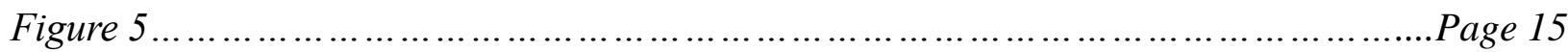

Generalized Workflow of Techniques Implemented in the Study

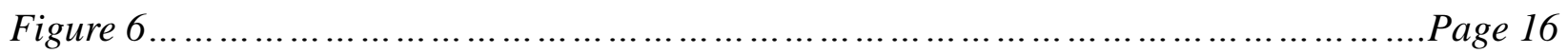
Crossline Comparison of Wavelet Frequency Enhanced WMR to the PSTM Seismic Signal

Figure 7 ......

Synthetic Seismogram-Mohr 37-059-24212 Well

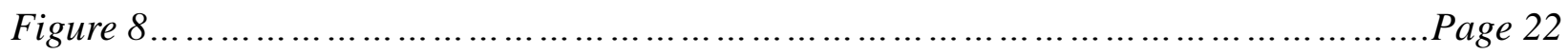

Two-way-Time Slice - Raw Data and WMR Enhanced Comparison

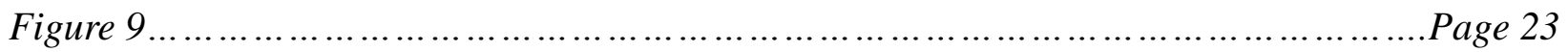

Time Structure Map - Raw Data and WMR Enhanced Comparison

Figure 10

Page 24

Root Mean Squared Amplitude (RMS) - WMR Enhanced Data

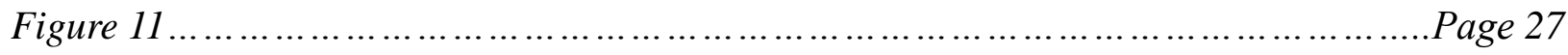

Most Positive Curvature Attribute - Raw Data and WMR Enhanced Comparison

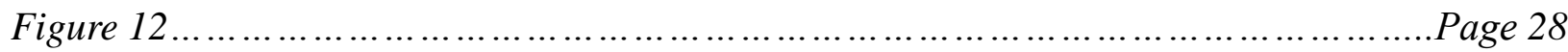

Variance Attribute - Raw Data and WMR Enhanced Comparison

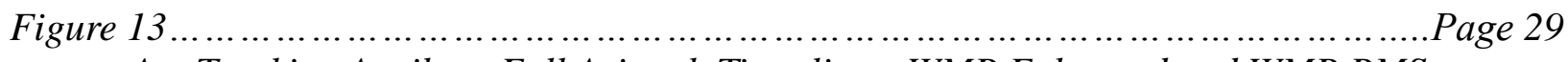

Ant Tracking Attribute Full Azimuth Timeslice - WMR Enhanced and WMR RMS

Comparison

Figure 14

Page 30

Map and Stereonet of Principal Stress During Marcellus Deposition 385Ma 


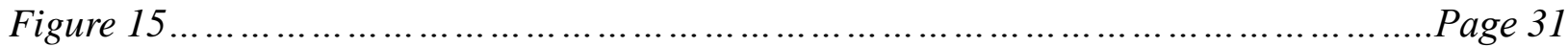
Hard-Calibration Crossplots - WMR RMS vs. Gamma Ray and Density

Figure 16 Page 34

Cross-Section: Interpretations of Basement Derived Structures and Silurian/Devonian Age Deformation

Figure 17

Page 35

Flake/Wedge Model Illustration

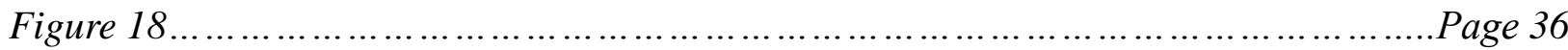
WMR RMS Ant Track Marcellus Interval Volume Azimuth $0^{\circ}$ to $90^{\circ}$ and $180^{\circ}$ to $270^{\circ}$

Figure 19 Page 39

Gravitational Sliding or Differential Contraction: Timeslice and Cross-Section of the Western Most Fault Structure

Figure 20 Page 40

Basement Structure Propagation: Cross-Section at Inline 198

Figure 21 Page 43

Cross-Sectional Progression of the Marcellus/Mahantango Detachment Fault and Localized Gravitational Sliding

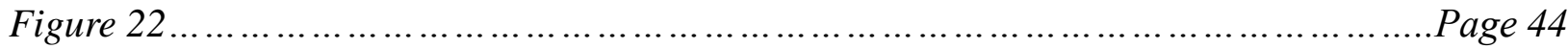
WMR RMS Marcellus Interval Volume Overlay on WMR RMS Ant-Track Marcellus Interval Volume

Figure 23 Page 48

Cross-Sectional Comparison WMR, WMR RMS and WMR RMS Ant-Tracking for Fault and Discontinuity Resolution and Clarification

Figure 24 Page 49

Photograph: Marcellus Sample of Fracture Plane Along a Calcite Vein

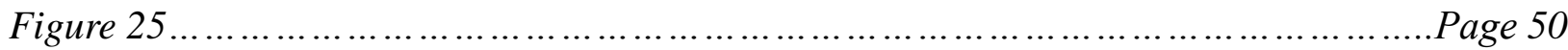

Cross-Section, Timeslice and Marcellus Interval Volume Depicting Structures: Fracture Networks, Faults and the Intra-Interval Marcellus/Mahantango Detachment Fault

Appendix I Page 59

Workflow utilized for attribute calibrations for Petrel 2010

Appendix II Page 60

Seismic data processing workflow completed by Echo Geophysical 


\section{Chapter 1: Introduction}

A detailed subsurface structural analysis was completed with the use of 3D seismic data from Greene County in southwest Pennsylvania, which is part of the Appalachian Plateau province, within the foreland basin of the Appalachian orogeny. Delineating and visualizing faults and fault-related folds and fracture orientation and intensity are critically important to the development of hydrocarbon reservoirs, but technologically challenging. Seismic attributes, including those commercially available and those not commercialized, were applied to enhance the visibility of critical structural features: faults, fractures and folds, for better understanding the hydrocarbon system.

To achieve these objectives, 3D seismic data was processed in Petrel, a product of Schlumberger, and seismic attributes were. A series of datasets including; maps, cross-sections, synthetic well-ties and cross-plots, were derived from the raw seismic signal, as well as conventional and advanced attribute-assisted seismic signals to define the reservoir geometry and continuity. Furthermore, advanced attributes were utilized to delineate deformational fabrics in order to resolve geologic details, such as discontinuities within and connectivity of the reservoir system.

\subsection{Previous Work}

3D seismic data is relatively new to the Appalachian basin; this study, to the best of the author's knowledge, is not preceded by published works pertaining to attribute analysis within the Appalachian basin of comparable extent. Therefore, this study may be utilized as an intrabasin analogue for future works concerning structural analysis in hydrocarbon exploration in this part of the basin. 


\section{Chapter 2: Geologic Setting}

\subsection{Stratigraphy}

The general stratigraphy in the central Appalachian region is displayed in figure 1a taken from Kulander and Dean (1986), Gao et al. (2000) and Wilson (2000), with modifications. A more localized stratigraphic column will also be utilized, figure $1 \mathrm{~b}$ taken from Laughrey and Baldassare (1998). Furthermore, the stratigraphic column from Boyce (2010), figure 2, will be referenced for intervals of Middle Devonian age of which the Marcellus Shale is the primary interval of interest.

\subsubsection{Marcellus Shale}

During the Acadian orogeny in Middle Devonian time (385Ma) the Marcellus shale was deposited as part of a clastic wedge derived from the erosion of the Acadian Mountains (Park, Barbeau, Rickenbaker, Bachmann-Krug, and Gehrels, 2010). R. C. Blakey (2010), figure 3, illustrates a paleo-earth reconstruction during this time. The Marcellus shale, organic rich black shale, was deposited on the Onondaga Limestone and resides below the Mahantango Formation; typically the Marcellus and Mahantango are referred to as the Hamilton Group. The Marcellus may be broken up into one to three separate intervals; upper, middle and lower, dependent on the existence either of the Purcell limestone or Cherry Valley (figure 3) (Boyce, 2010). These buildup and pinch-out sequences of carbonates may be attributed to short transgressive-regressive cycles (Lash and Engelder, 2011) during time of deposition or to local topographic highs and lows (Boyce, 2010). McDaniel (2006) indicated that sink holes and sags in the underlying Onondaga may link directly to the thickness of the Marcellus if deposition was congruent with structural events in the lower interval. It is also suggested that these thicker intervals tend to have a greater organic content and thus are likely more significant to hydrocarbon creation (Yanni, 2010; McDaniel, 2006). High organic content and fracture systems within the interval make the Marcellus shale a strong unconventional gas play (Laughrey \& Baldassare, 1998). 


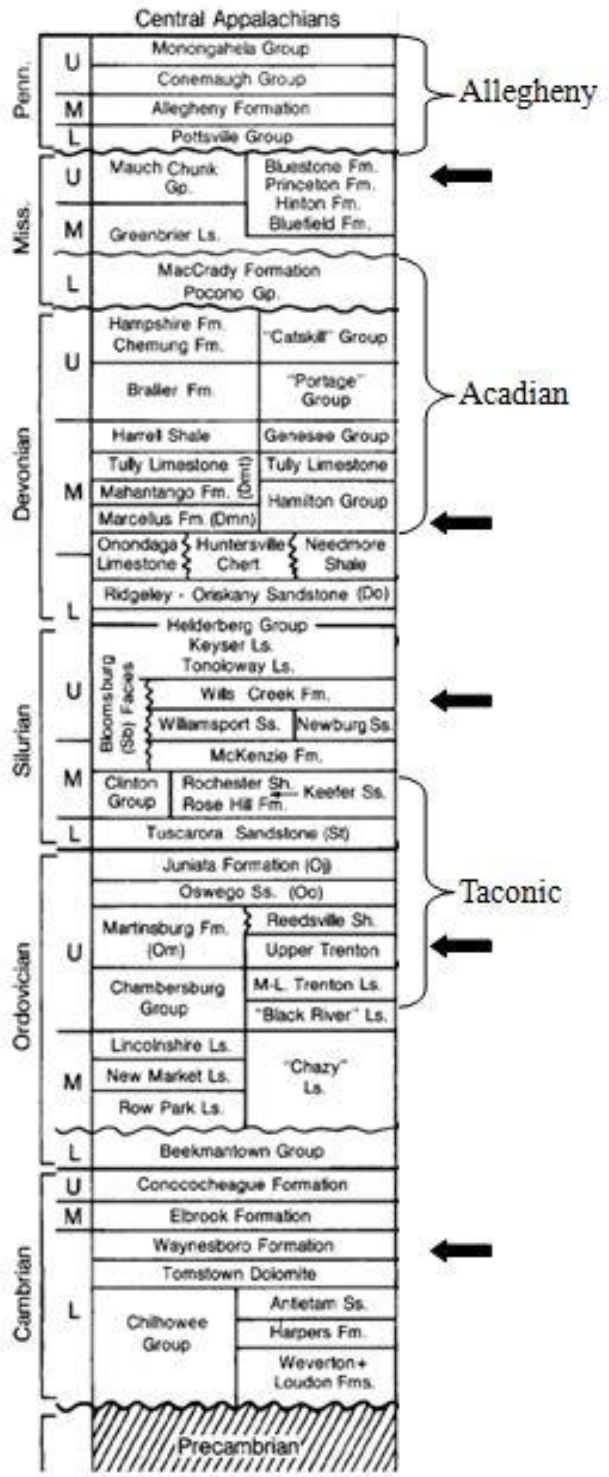

A

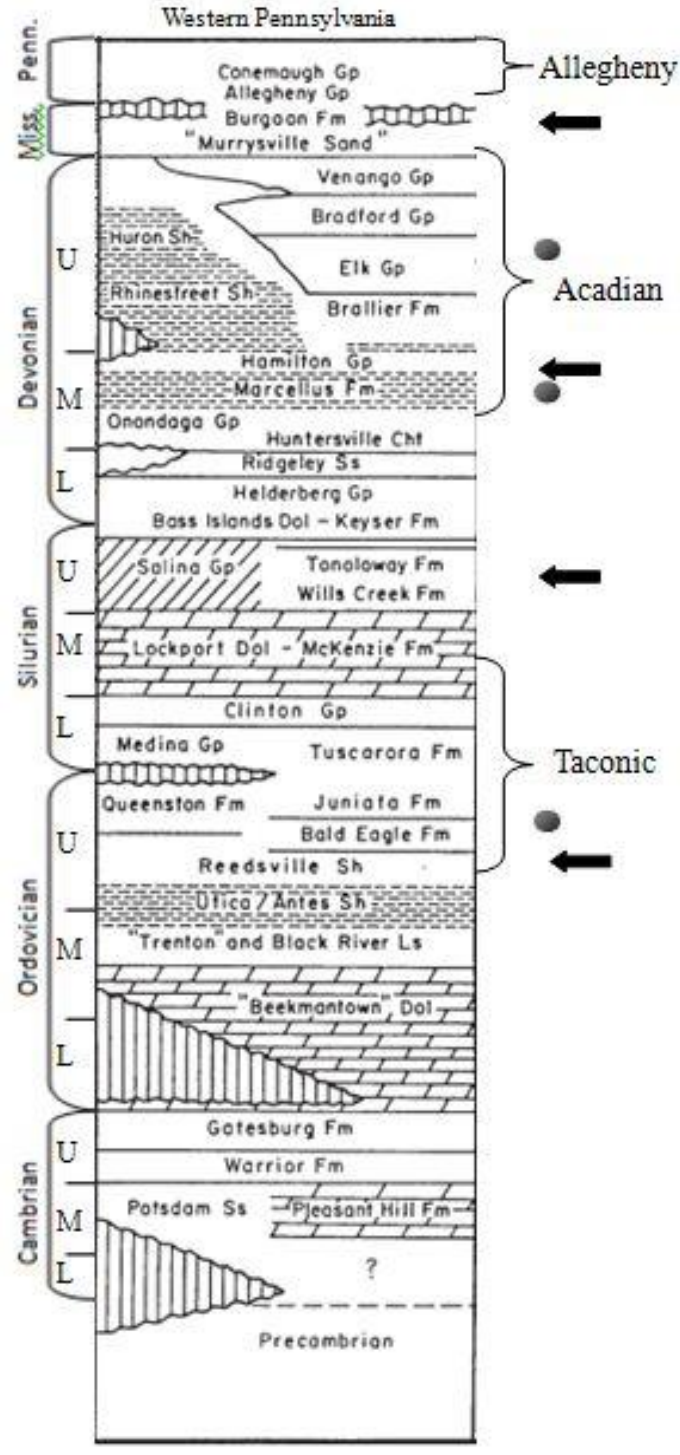

B

Figure 1.

A. Modified representation of stratigraphy, pre-Cambrian through Pennsylvanian in the central Appalachian as in Kulander and Dean 1986. Representation of tectonic events and detachments are referenced from Gao 2000, Wilson 2000, Harrison et al., and Boswell, R., 1988. Orogenesis is indicated by brackets while the darkened arrow symbolizes a detachment. B. Modified representation of stratigraphy, pre-Cambrian through Pennsylvanian in western Pennsylvania Laughrey and Baldassare 1998. Orogenesis is indicated by brackets while the black dots indicated potential source rocks as interpreted by Laughrey and Baldassare 1998. Darkened arrows symbolizes detachments. The red lines indicate the units referenced while interpreting the Middle Devonian intervals. 


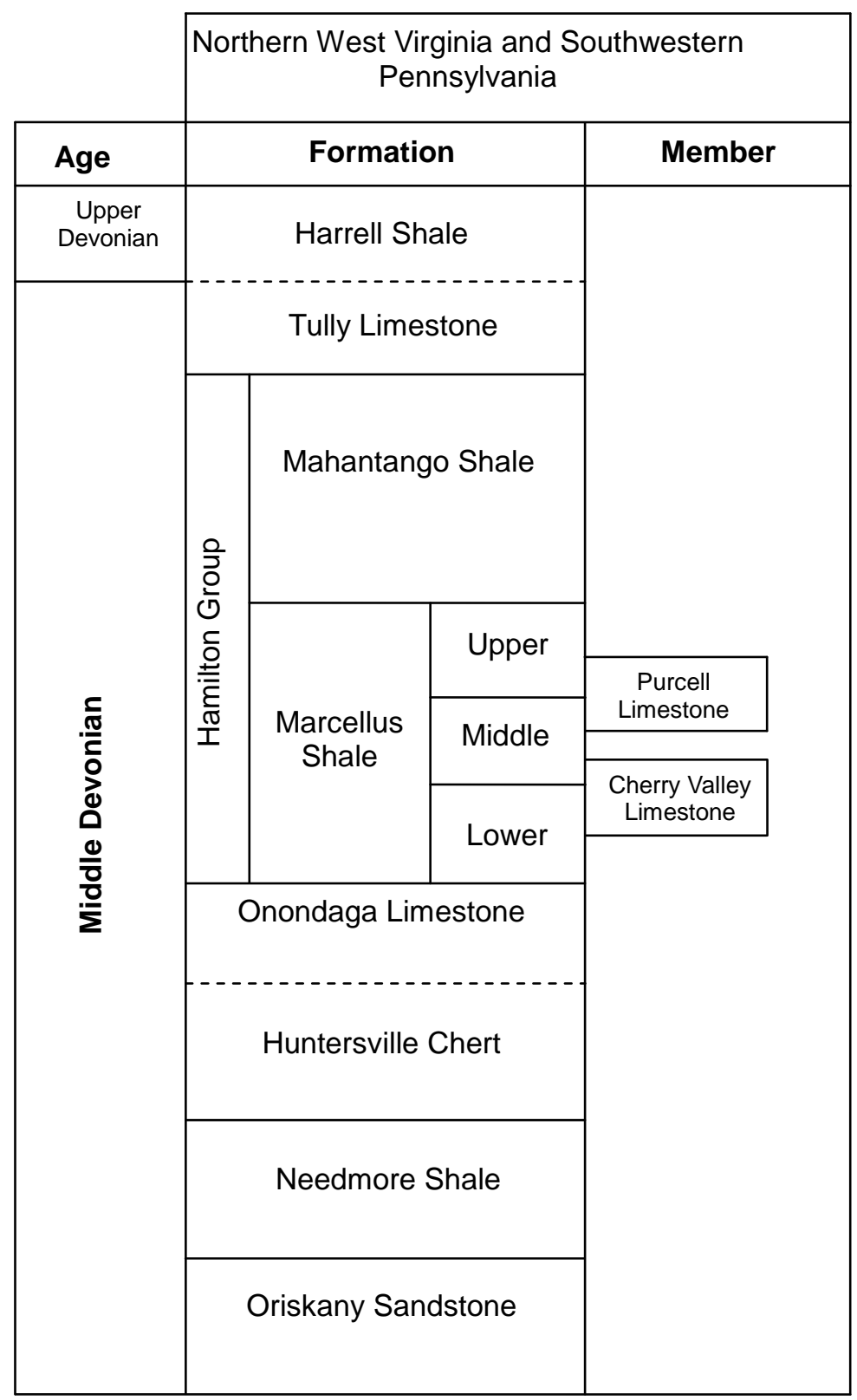

Figure 2.

Northern West Virginia and Southwestern Pennsylvania stratigraphic column, modified from Boyce 2010, modified. Dashed lines indicate location of unconformities. The Marcellus interval may be separated into an upper, middle and lower by the Purcell Limestone and Cherry Valley units. 


\subsection{Structure and Tectonics}

\subsubsection{Background}

The Appalachian Orogen is a compilation of three orogenic events which initiated in the Ordovician and extended through the Pennsylvanian: the Taconic, Acadian and Allegheny (Park, Barbeau, Rickenbaker, Bachmann-Krug and Gehrels, 2010). These tectonic events created a series of detached structures in the Paleozoic sedimentary section. Underlying these detached sections is a basement composed of elements associated with the Cambrian assemblage of Rodinia initiated by the Grenville Orogeny (Faill, R. T., 1997).Additionally, a rifting phase occurred during the Early-Middle Cambrian post-orogenesis. It has been well documented that these basement structures express themselves in overlying units (Boswell, 1988; King \& Zietz, 1978; Kulander \& Dean, 1986).

Regionally, decollements tend to be located in the Silurian Salina and shale units of multiple ages as they are structurally more susceptible to stresses caused by orogenic activity in the area. Included in these are the Mauch Chunk Group of the Upper Mississippian, the Mahantango and Marcellus intervals of Middle Devonian, the Upper Silurian Wills Creek Formation, the Upper Silurian Salina Group, the Reedsville Shale of the Upper Ordovician and the Waynesboro Formation in the Upper Cambrian. Harris, Marshak, and McBride (2004) describe Central Appalachian detachments in the Cambrian Waynesboro Formation, Ordovician Martinsburg Formation, Silurian Wills Creek Formation, Devonian Mahantango Formation and Mississippian Mauch Chunk Formation corresponding to their study in northeast Pennsylvania. Kulander and Dean (1986) also specify the same Cambrian and Ordovician detachments; while they and others suggest Silurian and Devonian detachments to be within such shale units as the Wills Creek and Marcellus (Boswell, 1988). Additionally, Kulander and Dean (1986) refer to an unconformity in place of the Mauch Chunk Formation detachment of Harrison et al. (2004).

Tectonic activity and structural components including joints and fractures are also important when developing a model for the Marcellus Shale as they may lead to an increased porosity within the reservoir and may also serve as potential migration pathways for hydrocarbons. Orientation of principal paleostresses may be determined by analyzing these faults, joints and fractures. With a better understanding of stress field orientations, more precise drilling may take place as drilling perpendicular to joints and faults promotes induced fractures and migration of hydrocarbons to the well; however, correct interpretations of principal stresses 
are made difficult as fluid-driven jointing and fracturing brought on by hydrocarbon maturation may lead to alterations in fracture orientation (Engelder, 2004). Other plausible modes of stress field, and thus jointing and fracture orientation, variations are discussed by Engelder and Whitaker (2006) who propose the existence of a pre-Alleghenian orogeny basin wide stress field. Overall, the study region is marked by episodes of compression, extension and subsidence accompanied by transpression and transtension, which occurred during sequential orogenic and quiescent periods.

\subsubsection{Rome Trough}

A failed rift, known as the Rome Trough, underlies the study area in the central Appalachian Basin (figure 4) as a series of grabens and extensional faults and contributed to mechanical extension (rift) and thermal subsidence (sag) which may have continued to affect sedimentation, maturation and hydrocarbon production (Shumaker and Wilson, 1996; Gao and Shumaker, 1996; Gao, Shumaker and Wilson, 2000; Edmonds, 2004) related to the Marcellus interval. The basement feature of grabens reaches into the Appalachian foreland in Kentucky, West Virginia and southwest Pennsylvania and are part of an interior rift system (Boswell, 1988). The eastern and western boundaries in southwest Pennsylvania were mapped through the use of seismic and well data; the Rome Trough encompasses Greene County, Pennsylvania (Gold, Alexander, Cakir, Doden and Root, 2005; Lewis, McDowell, Avary and Carter, 2009).

During subsequent tectonic activities, faulting related to the pre-existing graben structures were reactivated forming depressions during the Late Devonian (Curtis, J. B., and Faure, G., 1997). These reactivations due to regional tectonic events may be related to structural features developed in overlying units, extending up-section from the basement. Furthermore, structural lineaments normal or oblique to Rome Trough orientation may have been related to the early extension of the Rome Trough and overprinting contraction of the overlying units (Gao et al, 2000; Wilson, 2000; McDaniel, 2006).

\subsubsection{Structural Lineaments Related to Rome Trough Structure}

There are a number of proposed lineaments within southwestern Pennsylvania and northern West Virginia; the following are pertinent to the study locale: $40^{\text {th }}$ Parallel, Washington County and the Greene County lineaments (figure 4). In a broader context, these might be similar to the $38^{\text {th }}$ Parallel and Burning-Mann lineaments (Gao and Shumaker, 1996; Gao et al., 2000). These features are proposed based on gravity and magnetic anomaly data, igneous intrusions, 
such as kimberlite (Parrish and Lavin, 1982), by map discontinuities and present day fluvial patterns (McDaniel, 2006). Moreover, it is the general assumption that these cross-structural lineaments occur at pre-existing zones of weakness and may be indicative of crustal blocks. Parrish and Lavin (1982), account for kimberlite intrusions at the merger of structurally parallel and perpendicular zones. These emplacements are correlative of lineament location, specifically the Pittsburgh-Washington or $40^{\text {th }}$ Parallel lineament (Parrish and Lavin, 1982). Additional cross structural lineaments, the Washington County and Greene County lineaments border the study area, see figure 4, modified from Shumaker (1996), Kulander and Ryder (2005) and Gold et al. (2005).

The New-York Alabama lineament interpreted by King and Zietz (1978) and Stehltenpohl, Zeitz, Horton and Daniels (2010) as a right-lateral strike-slip basement anomaly with nearly $220 \mathrm{~km}$ of offset, is a north-east trending feature believed to represent Grenville-age suture zone. Gao and Shumaker (1996) suggest the $38^{\text {th }}$ Parallel and Burning-Mann Lineament are accommodation zones where extension is transferred between grabens of separate rifting segments. At these locations the trend of the Rome trough is modified and the geometry of grabens and sedimentation thickness become variable (Shumaker and Wilson, 1996; Wilson, 2000; Gao et al, 2000; Gao and Shumaker, 1996) (see figure 4 for a map of proposed lineaments).

\subsubsection{Taconic Orogeny}

The Taconic Orogeny began in the Middle Ordovician and is recognized as the collision of continental-arcs with the eastern margin of Laurentia, ultimately leading to the closure of the Iapetus Sea (Park et al., 2010; Karabinos, Samson, Hepburn, and Stoll, 1998). This collision developed into plate subduction and is attributed to the initiation of the current Appalachian basin structure (Castle, 2001). Post-Taconic tectonic activity includes granodiorite and tonalite plutons suggestive of subsidence and loading of the plate margin along with plate subduction beneath the Laurentia margin.

\subsubsection{Acadian Orogeny}

Well preserved in the northern Appalachians, the Acadian orogeny occurred as the microcontinent of Avalon collided, at an oblique angle with the eastern margin of Laurentia. In the southern and central Appalachians accretion of the Carolina terrane took place (Park et al., 2010; Taylor \& Toksöv, 1982; VerStraeten, 2004). Loading of the Laurentia margin during 
orogenesis generated subsidence eventually leading to the reactivation of the foreland basin approximately 385Ma, see figure 3 from Blakey (2010) for a paleo-earth reconstruction during these events. During this time, basin fill was subjected to eustatic changes as the basin flooded creating a shallow epicontinental sea with associated alluvial and deltaic environments (VerStraeten, 2004). The Catskill Wedge extending from New England to Georgia and Alabama, is linked to this process and the uplift and erosion of nearly $20 \mathrm{~km}$ of crust (Park et al., 2010).

\subsubsection{Allegheny Orogeny}

The Allegheny Orogeny by far had the most structural influence on the central and southern Appalachians. A result of an oblique, transpressive, rotational collision the Allegheny Orogeny resulted in the final closing of the Iapetus Sea and the creation of Pangea (Park et al., 2010; Taylor \& Toksöv, 1982). This fold-thrust event began in the Late Mississippian with continued deformation through the Pennsylvanian and is responsible for most of the crustal shortening throughout the Appalachian Orogeny (Edmonds, 2004). Additionally, Park et al., (2004) attributes the accretion of the Suwannee terrane, translation of previous terranes, magmatic activity and the development of a foreland fold-thrust belt in the central and southern Appalachians to the Allegheny Orogeny. 


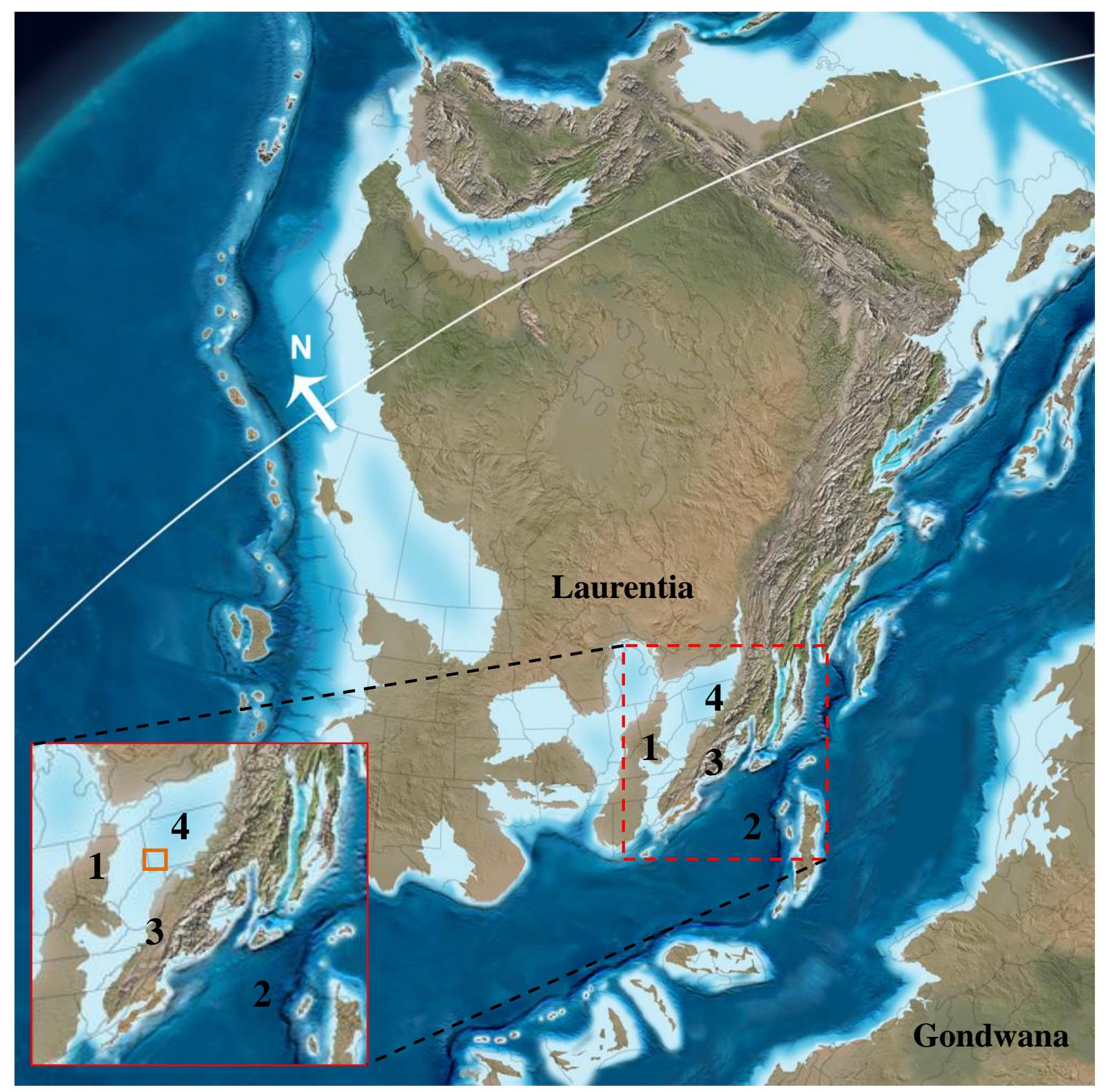

Figure 3.

Representation of the earth during the Acadian Orogeny and time of Marcellus shale deposition, Middle Devonian (385Ma). The orange box signifies the study area. 1. The Cincinnati Arch. 2. Rheic Ocean. 3. Acadian Mountains. 4. Appalachian Basin. Modified from Blakey (http://jan.ucc.nau.edu/ rcb7/RCB.html). 


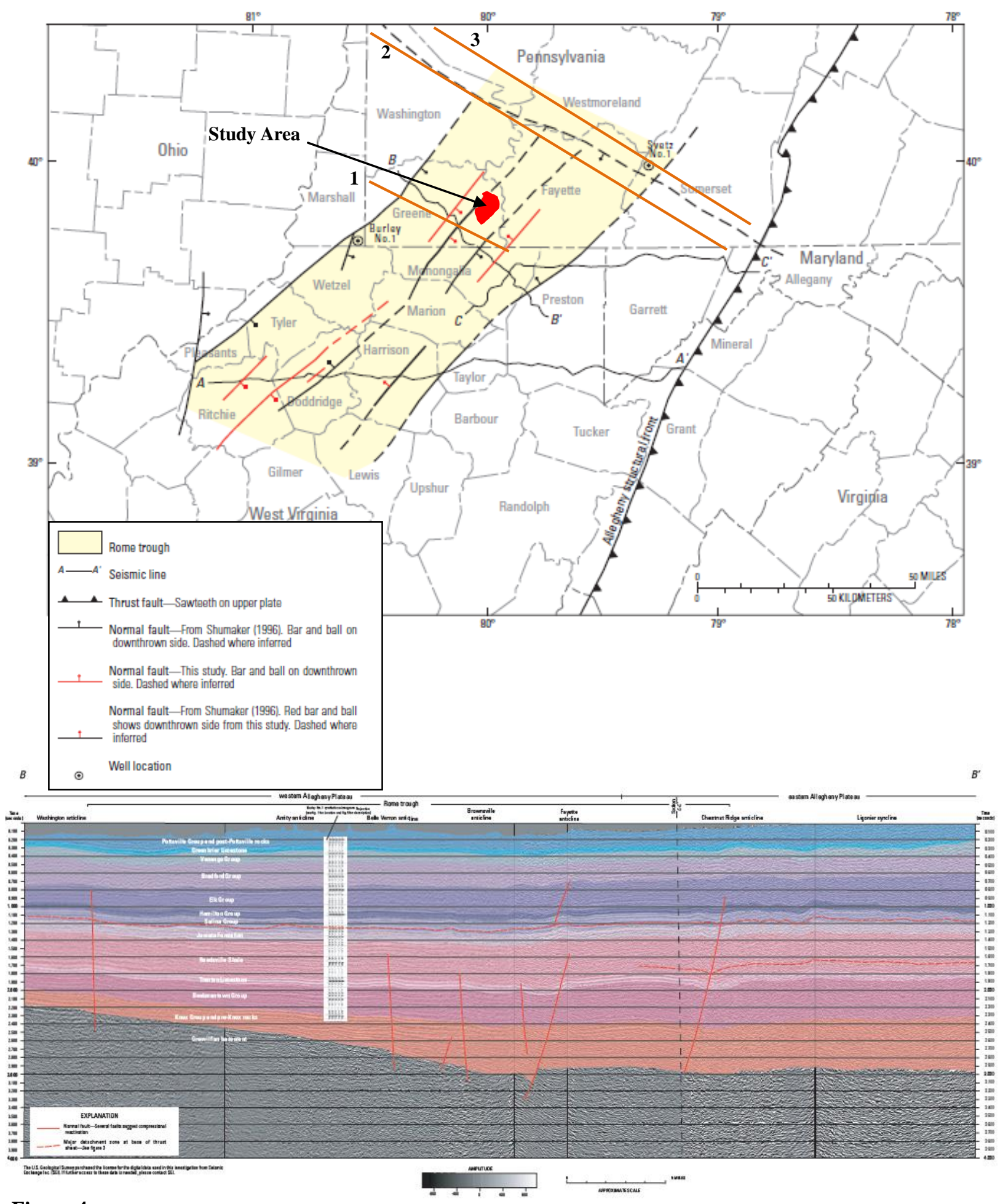

Figure 4.

Basement structure overlay on a regional map acquired from Google Earth. The study area is outlined in black within the white square. Western extents of the Rome Trough are shown by teal dashed lines, lineaments are signified by red lines. Number 1, 2 and 3 signify the Greene County, Washington County and $40^{\text {th }}$ Parallel lineaments respectively. Modified from Shumaker (1996), Kulander and Ryder (2005) and Gold et al. (2005). Reference Gold et al. 2005 for a more complex rendition of basement contours and faulting. (put link in here?) 


\section{Chapter 3: Data and Methodology}

\subsection{Data}

\subsubsection{D Seismic Survey}

The 3D seismic dataset encompasses approximately $25 \mathrm{mi}^{2}$ in Greene County, southwest Pennsylvania. The survey was conducted by Geokinetics USA Inc. for Energy Corporation of America. The study region is shown in figure 4. Two source types were used in this acquisition, dynamite and vibroseis. Dynamite, charge size $2.2 \mathrm{lbs}$ was placed at a $20 \mathrm{ft}$ depth, while two vibseis at $62,000 \mathrm{lbs}$ and three vibseis at $48,000 \mathrm{lbs}$ conducted six sweeps with a sweep length of eight.

The projection coordinates for this data set are North American Datum of 1927, Pennsylvania South. Additionally, the bin size is 110 feet in the inline and crossline making for a clean shoot as a larger offset allows for a higher fold; the datum of the study area is 1200 feet, the replacement velocity $12000 \mathrm{feet} / \mathrm{second}$, and the sample rate was set for 2 milliseconds. The crossline orientation is $1.5^{\circ}$ from geographic north and for this study was considered due north. The data was processed in 8-bit resolution in time domain by Bill Wepfer of Echo Geophysical Corporation; see Appendix II for a list of processing parameters. Two processed volumes were available for analysis, Kirchoff post-stack migration and a post-stack migration. The post-stack migration volume was used in this work.

\subsubsection{Well Logs}

Access to well data was granted by Energy Corporation of America. Well data utilized to create synthetic seismograms and well ties to assist with interpretations of the seismic data set. These wells were either drilled by ECA or were acquired, in some capacity, from another source. These wells were analyzed and seismic ties were created for well log correlations and defining interval locations. Correlating well logs throughout the study helped develop a more complete structural understanding across faults and structurally complex zones.

Four wells were utilized in the completion of seismic attribute calibrations; 37-05924666, 37-059-24212, 37-059-25278MH and 37-059-24743. Synthetics for each of these wells were created and were thus correctly positioned for the calibration, Appendix I. 


\subsection{Methodology}

\subsubsection{General Workflow}

This study commenced by importing the seismic data in .segy format to the geophysical modeling software Petrel by Schlumberger. Input of well data followed this initial procedure. At this stage in the process, the typical workflow for seismic data analysis was followed. First, synthetic seismograms were created in order to tie reflection events, peaks and troughs, to respective stratigraphic intervals. Once a satisfactory tie was obtained horizon tops were picked and quality control on the tops was completed. Horizon surfaces were then created and surface attributes were extracted and analyzed. Volume attributes; volumetric curvature, variance, structural dip, azimuth, instantaneous frequency, instantaneous phase, RMS and ant tracking were then run on the raw 3D data set and analyzed in inline, crossline and timeslice views. An initial interpretation of the study area was completed, accompanied by fault picking, in order to develop an idea for the structural styles present.

During the aforementioned procedures, the raw seismic signal was processed in Paradigm Geophysical's software module VoxelGeo to apply the waveform model regression (WMR) attribute developed in-house at West Virginia University (Gao, D., 2002, 2004). This data was exported from VoxelGeo, imported into Petrel and the seismic analysis procedures were again followed with this new volume. However, synthetic seismogram creation for the WMR volume was not feasible as the attribute removes trough data through the use of a regression algorithm. Interpretations of both data sets were then combined and a final interpretation of the study area was developed. A generalized workflow of the processes completed is given in figure 5.

\subsubsection{Attributes}

New attribute analysis and visualization technologies were applied to create an increased resolution of the structure and, to a lesser extent, stratigraphy in the subsurface. The nature of faults, including orientation, dip, continuity and intensity as well as fracture analysis and attribute calibrations were studied to determine hydrocarbon potential and prove the usefulness of 3D data and attribute assisted interpretations in the Appalachian region and other unconventional reservoirs.

Attribute analysis and interpretation of structural entities may better indicate the potential of faults and fractures in the Marcellus in this region. Application of advanced attributes to the 
data may be worthwhile in well planning and geo-steering operations as fracture and fault characterization may lead to improved plays.

\section{Traditional Attributes}

Traditional attributes were implemented to assist in the visualization and interpretation of the data. These methods include: instantaneous frequency, root mean squared amplitude (RMS), variance, structural dip and curvature. Instantaneous frequency, variance, structural dip and curvature are useful for enhancing structural components most notably, continuity and path deviation of faults, making them particularly useful to this study. RMS amplitude highlights density and/or velocity contrasts and is thus useful for discerning facies and detecting hydrocarbons but is not particularly useful for distinguishing faulting and fracturing.

Instantaneous frequency may be indicative of bedding thickness and thickness variability, facies delineation and /or interval and facies boundaries, as well as, structural discontinuities as they pertain to facies bounds (Zeng, H., 2010). Variance distinguishes structural dissimilarity through a lateral comparison of seimic waveforms (Marfurt, Kirlin, Farmer, and Bahorich, 1998); neighbor-to-neighbor evaluations of wiggles reveal a coherent or incoherent pattern, the latter defines lateral discontinuities that may be indicative of faulting. 2D curvature is the measure of lateral change in radius along a curve at any point and is used to define the structural variations; anticlinal, positive curvature and synclinal, negative curvature features, in a time slice, horizon or horizon window (Sigimondi, M. E. and Soldo, J. C., 2003; Chopra, S and Marfurt, K. J., 2010).

\section{Advanced Attributes}

Three advanced seismic attributes were used in this study, two of which were accessible within the interpretation module. Volumetric curvature and ant tracking are available though Petrel 2010, and may also be available in other geophysical modeling softwares; nonetheless, these attributes are considered advanced as they are capable of deriving more information from seismic signals than the aforementioned attributes and are less accessible in other modules typically used when exploring the Appalachian basin. Volumetric curvature is essentially the measure of curvature at a point in relation to a surface created by two orthogonal planes. Volumetric curvature may be derived through searching the apparent dip of reflectors in 3D (Yan, Wen, Tang, and Gu, 2011). Ant tracking traces faults and fractures by introducing a set of parameters including a initial ant boundaries, track deviation, step size, legal steps required for 
and illegal steps allowed for the continuation of tracking a discontinuity or edge and stop criteria. Schlumberger in Petrel 2010 use the analogy of ants finding their way back to the nest. They will follow the shortest path, in this case the discontinuity or edge, and release pheromone for other ants to follow, analogous to the legal steps required, illegal steps allowed and stop criteria. The other is an original attribute called a constant-phase waveform model regression that was recently developed based on an early texture model regression concept (Gao, 2002, 2004).

\section{Waveform Model Regression}

The WMR algorithm uses a linear least-mean squares regression to calibrate likeness between a wavelet model and seismic data. Customized WMR algorithms make it applicable for use in defining seismic structures, facies analysis and reservoir properties (Gao, 2002, 2004). Overall, a more elegant interpretation of structural and stratigraphic characteristics may be achieved with the implimentation of this advanced seismic attribute.

Constant-phase WMR converts regular wiggle trace into a structurally-enhanced attribute. It is a multi-step function completed repeatedly along a wiggle trace. This method focuses on defining and enhancing the visibility of the folds and faults to aid structural intepretations in both map and cross-sectional views. A brief functional analysis of the processes and mathematics will suffice as the intent of this study is to apply this advanced attribute to the 3D seismic data and to better visualize and interpret the seismic structural features that might not be easily recognizable from regular amplitude data (Gao, 2002, 2004).

Constant-phase WMR is advantageous when compared with regular wiggle-trace data as constant-phase WMR algorithm increases the waveform frequency through waveform to constant phase correlation and by the application of the absolute value while the linear leastsquares regression acts as a filter leading to the enhancement of signal-to-noise ratio. In map view this translates to structure and stratigraphic features being clearly delineated in their lateral extent, trend and geometry. In cross-sectional view, it helps resolve both stratigraphic and structural features due to the enhanced frequency of the data (see figure 6). 


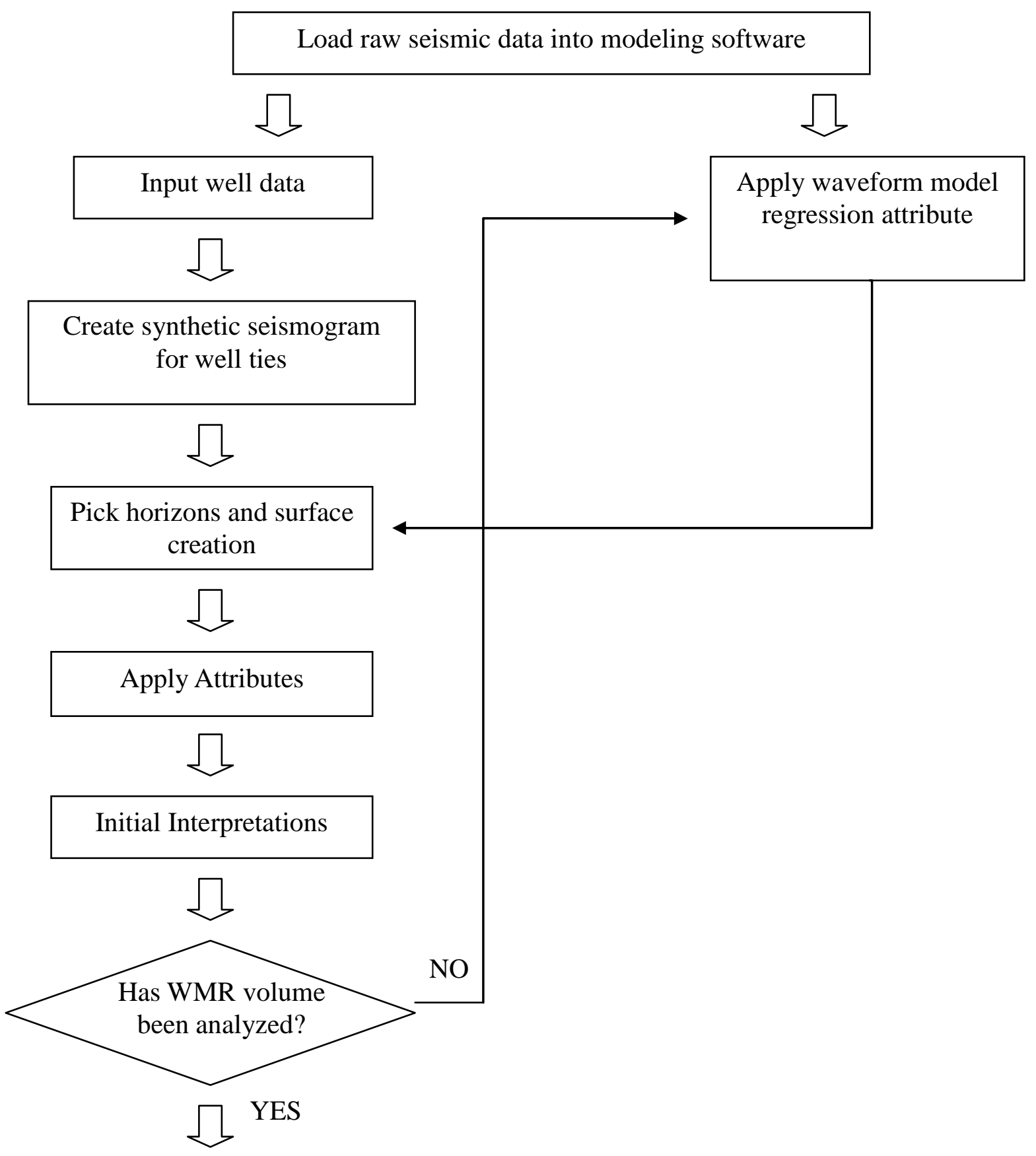

Soft and hard calibrations

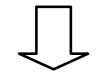

Final Interpretations

Figure 5.

General workflow followed for this study. Processing of the data with the WMR attribute occurred coincident with the input of raw data into Petrel 2010, 

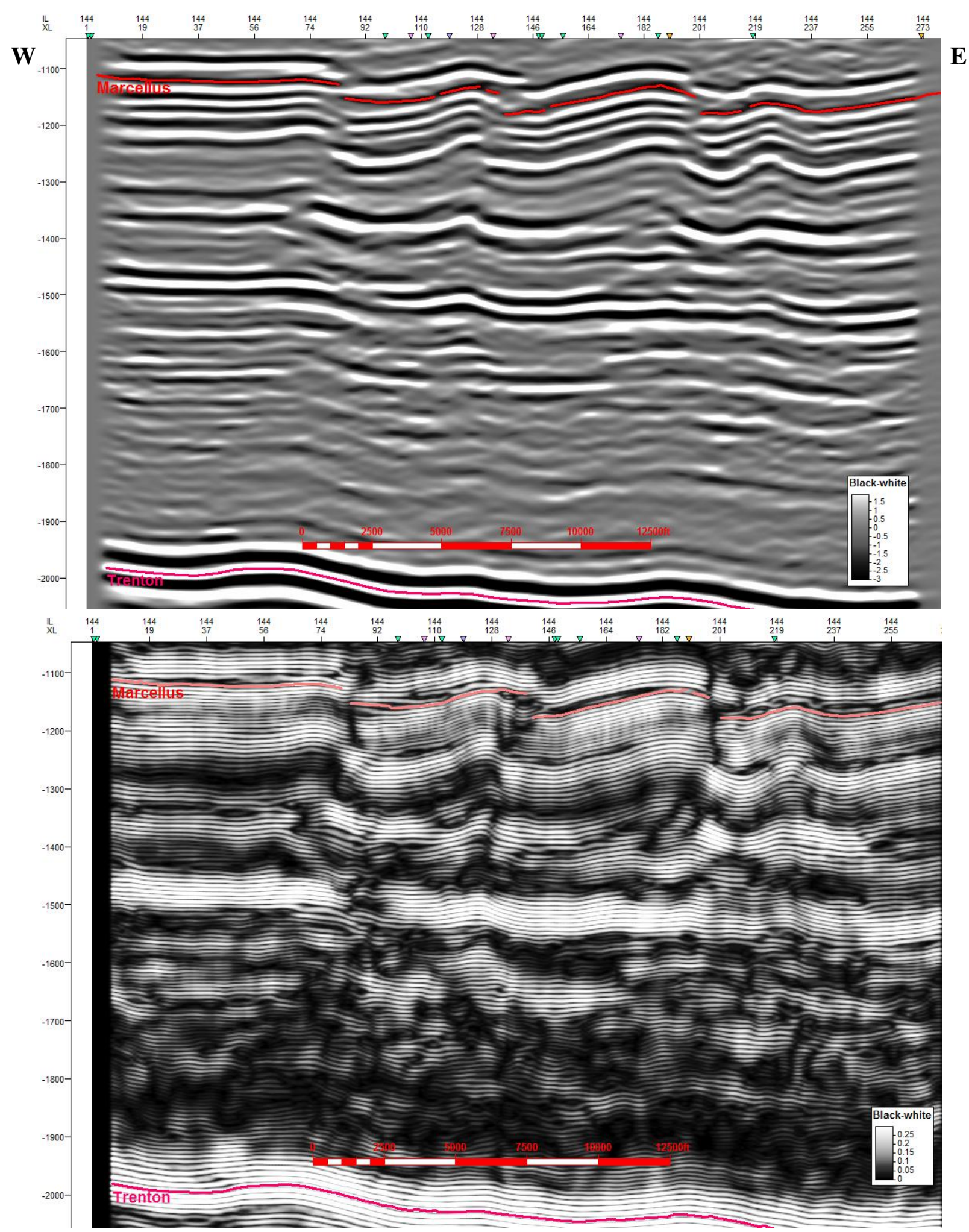

\section{Figure 6.}

Compares PSTM amplitude data and data processed with the newly developed WMR algorithm. Structural details of the subsurface where lacking in the PSTM volume window (top) are clearly defined with the WMR method (bottom). 


\subsubsection{Data Extraction and Calibration}

Classic geophysical analysis in the Appalachian basin is characterized by synthetic well ties, horizon generation, fault picking, attribute extraction and interpretations deriving from the merger of these methods. Interpretations based on this workflow typically result in a work correlative to an overall structural style of a region, but these methods tend to overlook additional data that may be aquired through a correlation of attribute-to-attribute or attribute-towell data, known as calibration. Attribute correlations/calibrations are done in two ways soft-tosoft data or soft-to-hard data, otherwise defined by the terms soft-calibration and hardcalibration. Any data that is not extracted from a tangible sample (i.e. well logs) are considered soft data, while the tangible sample itself is considered hard data. Soft data is typically attribute data such as frequency, variance or curvature. A soft calibration, attribute-to-attribute, or hard calibration, attribute-to-well log, are two advantageous methods that can lead to a more robust analysis of a region.

\section{Soft Calibration}

Soft calibration is typically performed in the absence of well control where hard calibration is not possible. Instead, comparisons between two or more quantitative values derived in some way, typically by the application of attributes, from seismic analysis are used to provide additional insight to the interpreter. As an analogue, a mathematical attribute derived from a statistical analysis (e.g. the WMR data) of an interval defines only a mathematical function of that interval. This data alone though relevant to the interval, may not effectively define the true rock properties of the interval. To circumvent this, a correlation to another attribute, either mathematically derived or signal derived, may be utilized to define the significance, by mathematical correlation or visual inspection, of either attribute. These calibrations can then be correlated to hard data to define their physical rock properties.

\section{Hard Calibration}

Hard calibration procedures are implemented in cases where well log data is accessible and attribute application and analysis have been completed. This method is advantageous as a tie of soft seismic data to rock properties may define a specific rock property highlighted by a seismic attribute. By identifying a correlative property for an attribute, interpretations of an attribute may yield conclusive results and make it possible to effectively map rock properties of 
an interval of interest. Reference Appendix I for a model of the procedures used in Petrel 2010 to complete hard calibration. 


\section{Chapter 4: Results}

A number of goals for this research are concentrated on the delineation of structural features such as faults /fractures and their connectivity, intensities and continuities. It is therefore relevant to conduct further analysis through attribute-assistance to resolve features and properties of rocks unrecognizable by visual inspection of seismic waveforms. Procedures mentioned in the General Workflow and Appendix I were followed to compile evidence necessary for accurate interpretations of structural styles in the study area. Acquired data are presented here in map, cross-section and cross-plot form. Additionally, processing of raw seismic data using advanceattribute application is a necessary step to increase the resolution of subsurface structural features. Reprocessing by way of waveform model regression, significantly enhanced the visibility of structural fabrics and signal-to-noise ratio of the original data acquired from Energy Corporation of America, markedly enhancing the definition of characteristic structural styles in this portion of the basin, figure 6 .

\section{$4.12 D$}

Initially, a synthetic seismogram was created to tie the seismic data to well data, a necessary step in seismic exploration (figure5); in figure 7 a synthetic seismogram is shown to correlate well tops to the seismic signal. The general workflow for picking horizons, creating surfaces and tracking faults was followed to develop a foundation from which attributes would be applied and eventually interpretations could be completed. Horizons were picked at intervals of high acoustic impedance, of primary interest, the Marcellus, Onondaga and Tully intervals were picked referencing the Mohr well, 37-059-24212, see figure 7. Quality control was completed on the horizons twice before surfaces were created and faults picked; although some horizons required additional revision. Surfaces were then created; smoothened and surface attributes were applied.

Figure 8, is a comparison of the WMR to the PSTM data at a two-way-time slice at $1130 \mathrm{~ms}$; figure 9 is a time structure map of the Marcellus interval derived from the WMR and PSTM volumes. Observations of these figures reveal the enhancements made to the data set through the application of the WMR attribute. In figure 8, the dips of beds, as well as discontinuities are better defined in the WMR data, while the delineation of bedding and dip is poorly defined in the PSTM data. Subtle structural features such as topography, highlighted by 
contours in figure 9, are refined. Also in figure 9, fault 2 in the WMR data decays in the south while in the PSTM data is propagates the length of the data set from north to south. Additionally, fault 3 in the WMR data extends north to the edge of the data; this does not hold true in the PSTM data. By comparison, in figure 10, the RMS amplitude values of each volume correlate well; however, the WMR RMS values, are constrained to a smaller than the PSTM RMS. The high correlation of the RMS values from each volume is expected as the WMR attribute utilized the amplitude from the PSTM volume in the algorithm.

2D maps and surfaces, figures 8 through 10 reveal three major anomalies trending northeast in a step-down manner, becoming progressively deeper, from west to east across the study area. The deepest part of the study area is located farthest to the east, bordering a large structural feature, figures 8 and 9 highlight these features and show the progressive deepening of the study area.

Though a number of structural features can be inferred from the above data, to develop a more in depth view of the seismic, 2D surface attributes were accompanied by the addition of 3D volumetric attributes. These attributes include RMS amplitude, curvature, structural dip, gradient, variance and ant-tracking. In this study, attributes which focus on the enhancement of the resolution of structural components were utilized as multiple benefits arise from the application of these volumetric attributes. Primarily the ability to cycle through inlines, crosslines and timeslices increases the dexterity of the interpreter allowing for an improved visualization and enhanced understanding of the seismic volume. Additionally, calibrations may be completed more accurately as a refined volume may be referenced for correlation rather than an averaged attribute value, a limit of the $2 \mathrm{D}$ surface attributes. 


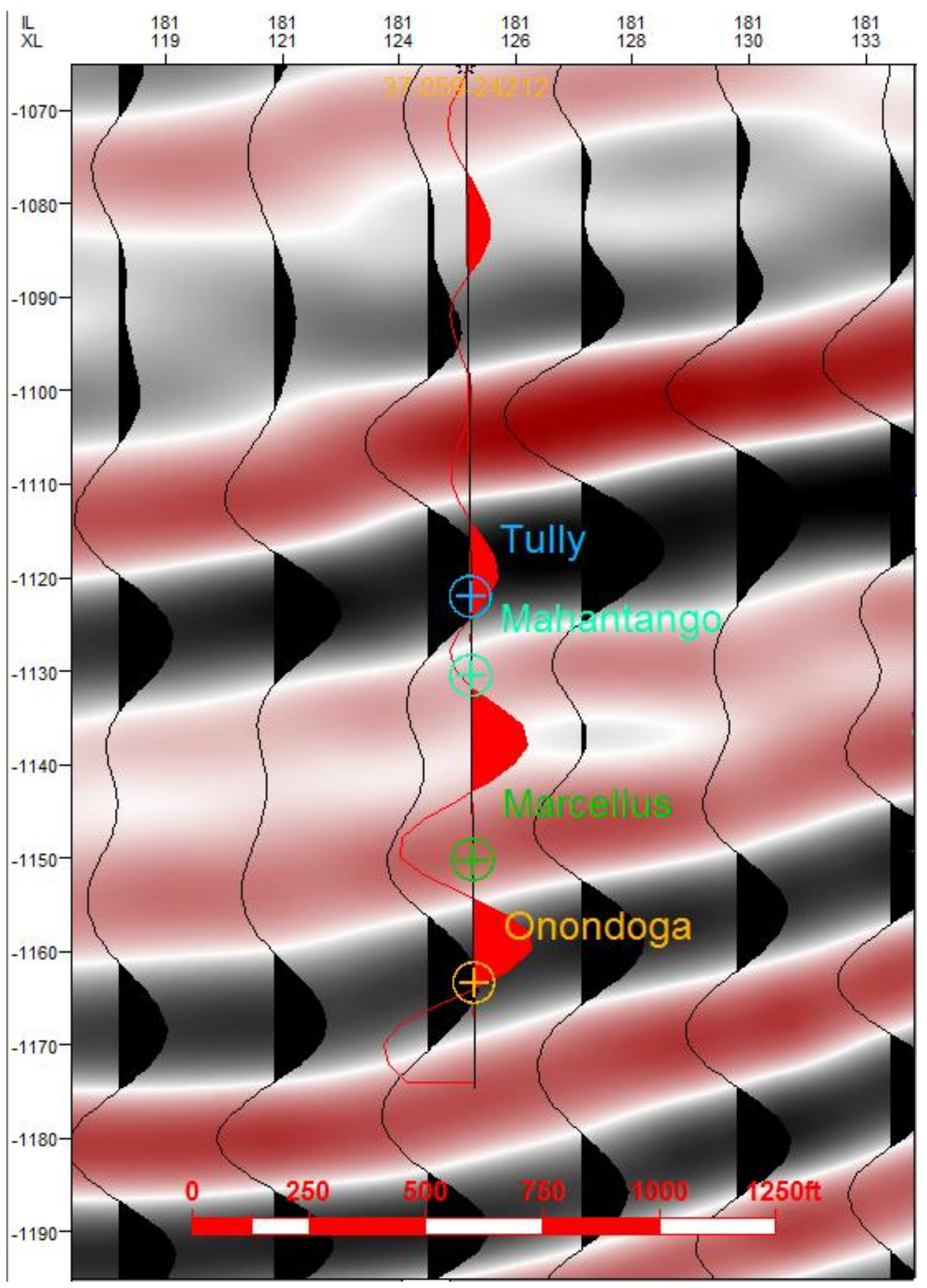

Figure 7.

Synthetic seismogram derived from the PSTM signal in the 37-059-24212 well. The synthetic signal is adjusted to amplitudes of likeness; the interval tops are correlated to waveform peaks and trough for horizon picking. 

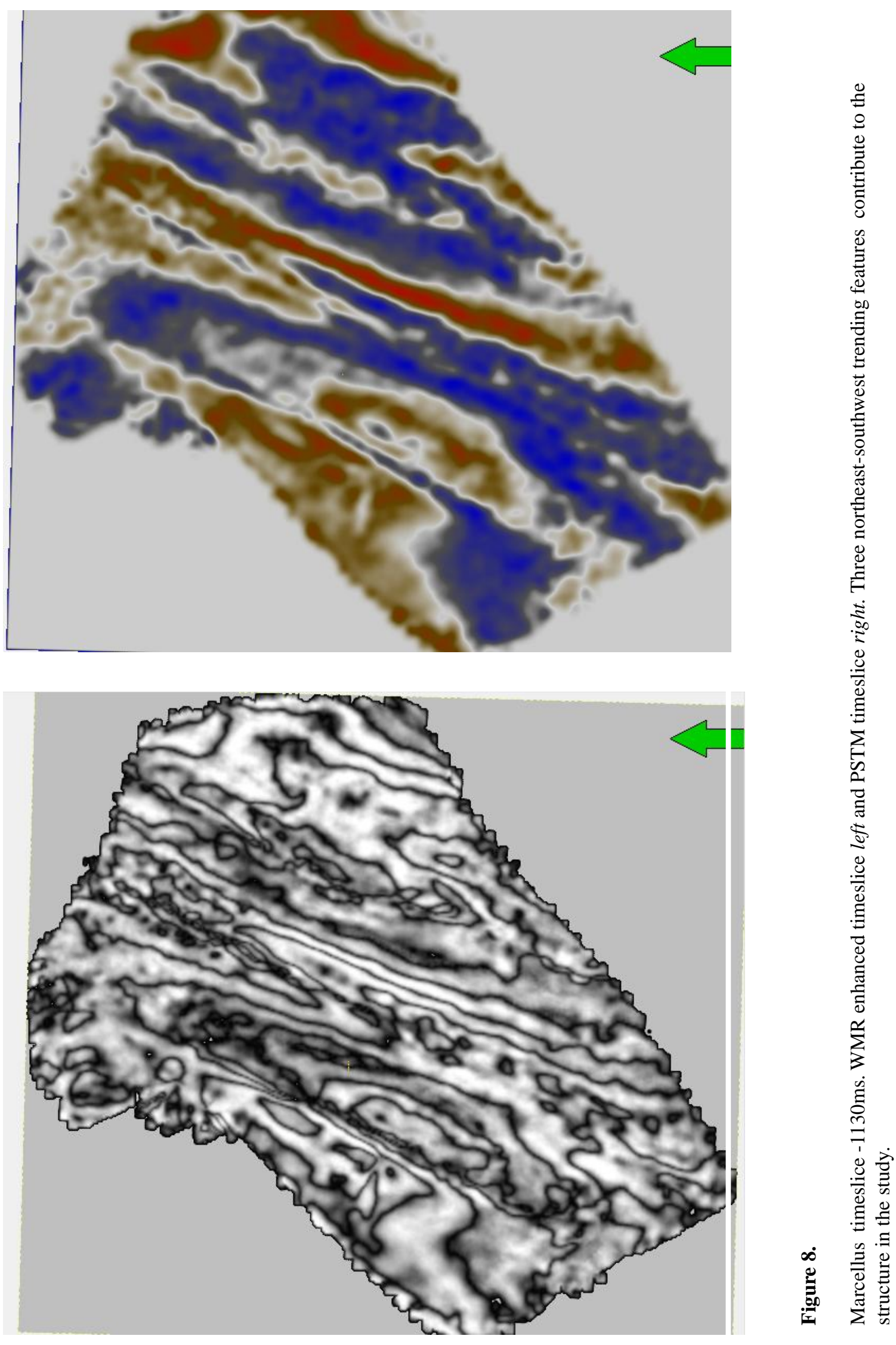

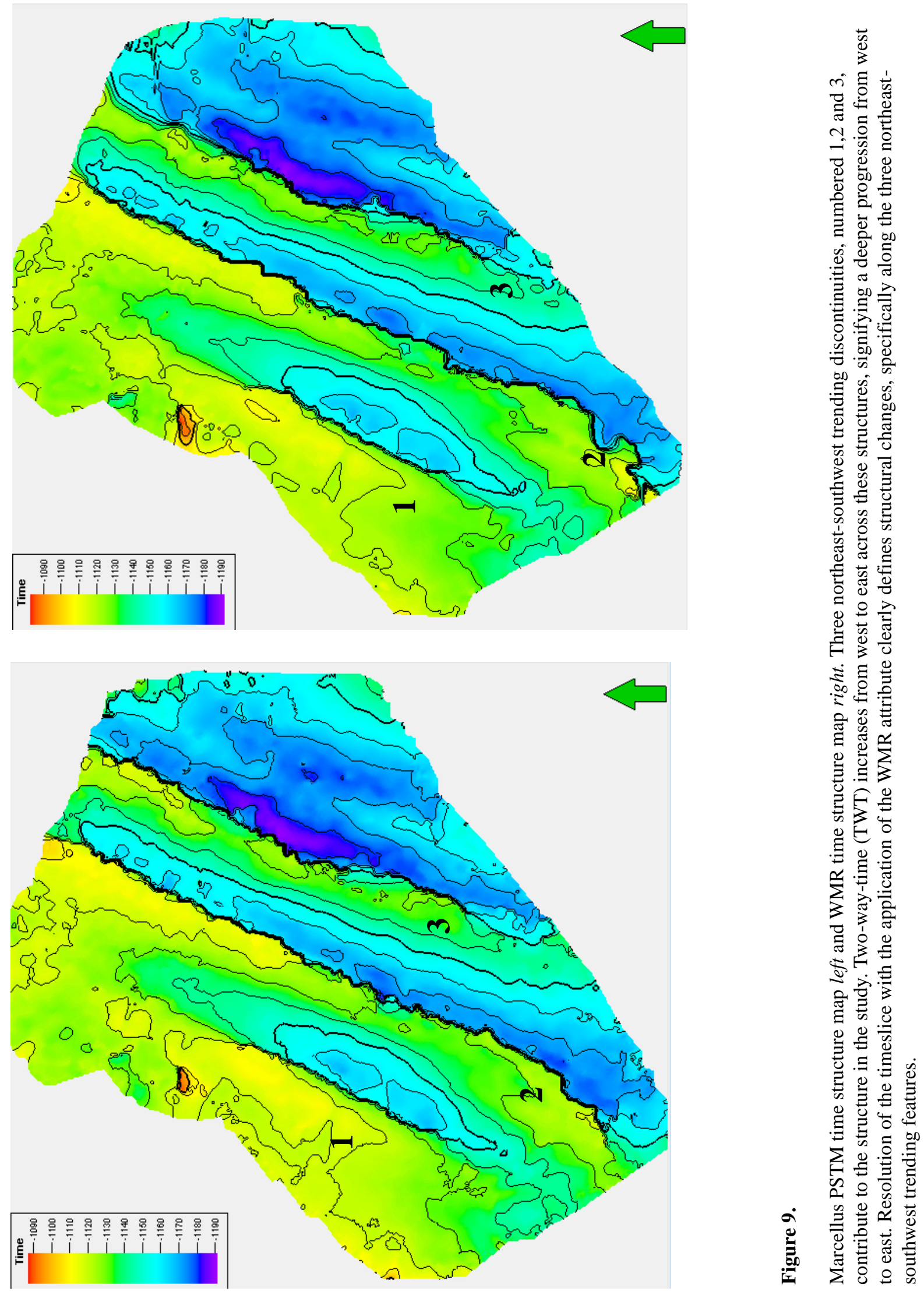


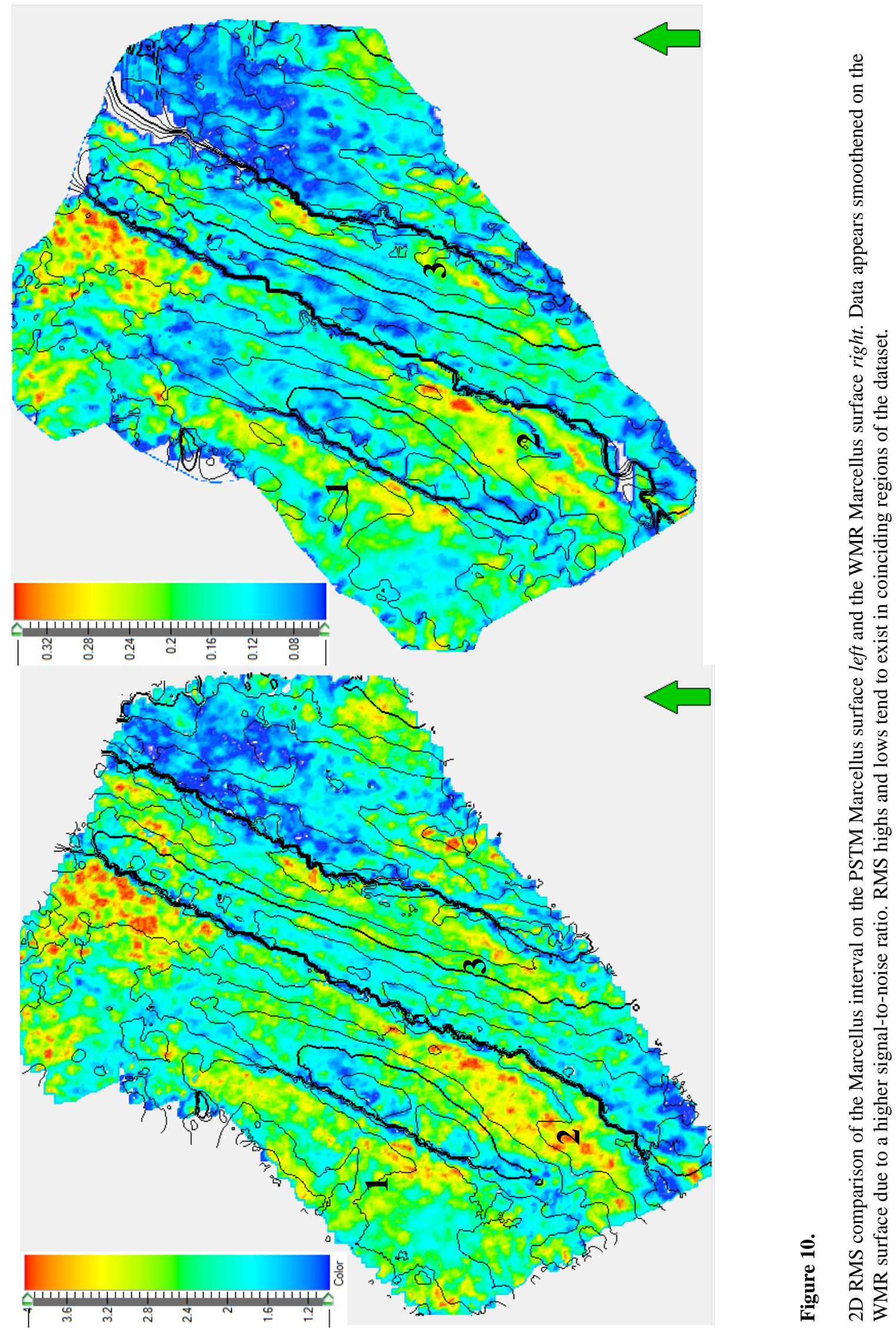




\section{$4.23 D$}

The WMR attribute and volumetric smoothening were applied to the dataset prior to further attribute introduction. Both methods enhance the resolution of the seismic signal, in two alternative manners. The WMR attribute focuses on the delineation of structural features through frequency enhancement and wavelet correlation, as well as noise reduction; volumetric smoothening uses a bandwidth filter to enhance the signal-to-noise ratio, however; the clarity of the smoothened data also removes valuable information in the signal. Nonetheless, this smoothened volume is utilized as reference for comparison of the WMR volume, to a traditional regular seismic volume. In most instances, the WMR volume yields cleaner result; local structures are more clearly depicted with the application of the WMR attribute see figures 8 and 9.

Most-positive and most-negative curvatures are important to the interpreter as they highlight zones of possible fractures; most-positive curvature is depicted in figure 11. The PSTM data with the application of the curvature attribute appears to yield better resolved curvature volume (figure 11). However, this is unlikely the case, as the signal-to-noise ratio is increased and noise is removed with the WMR method. Additionally, the data was analyzed in TWT (twoway-time) which does not account for the variable of velocity. Curvature analysis completed in TWT may therefore be skewed resulting in a biased interpretation. However, some analysis may still be completed. As an example, a closer inspection reveals fine details of the structure may be derived from the WMR most positive curvature whereas the raw signal does not allow for such resolution.

To further delineate structure in the study area, variance was applied, as it laterally evaluates continuity/discontinuity of amplitude values from wavelet to neighboring wavelet, essentially mapping the continuity of faulting over a specified interval or timeslice as pictured in figure 12. The PSTM variance attribute maps nearly continuous faults, signified by the yellow and orange colors in the image, and may neglect smaller amplitude variations. In both timeslices multiple faults may be interpreted (see labels in figure 12), countering the idea of three main thrust faults represented in figure 8 through 10 as fault 1,2 and 3. Upon comparison with the WMR variance map, the discontinuities identified by the PSTM data may be interpreted as a conglomerate of smaller discontinuities. Additionally, the PSTM overlooks a possible crossstructural feature, indicated by a red arrow on the WMR map. Another feature of variance is its 
potential for defining regions of thickness change within a given interval. In addition to faults and fault patterns, when combined with other attributes, specifically frequency, zones of interval thinning may be mapped.

Ant tracking, figure 13, traces faults and fractures by introducing a number of steps both incorrect and correct, a percentage of inconsistency and a deviation or number of voxels searchable around the fault as parameters for mapping, see section 3.2.2, Advanced Attributes. Furthermore, azimuthal search parameters and dip parameters may be set using a stereonet in the input window. Figure 13a is representative of a full azimuth search with dips above $30^{\circ}$ defined within the WMR attribute volume, at a time slice $-1150 \mathrm{~ms}$. Figure $13 \mathrm{~b}$ is representative of PSTM full azimuth ant-tracking run on a variance volume. By comparison, ant-tracking from both volumes define a number of discontinuities within the data set, indicated in figure 13 , in addition to the three main thrusting features shown in figure 8 through 10. PSTM data has a lower event recognition in contrasts to the WMR ant-tracking which distinguishes multiple zones of discontinuous low dipping $\left(30^{\circ}\right.$ to $\left.45^{\circ}\right)$ which may indicate a more complex underlying structure, see figure 13a. The WMR ant-tracking volume detects discontinuities, including possible crossstructural features and oblique to structure features and fault continuity, orientation and propagation at a superior level than that of the PSTM ant-tracking.

Automatic fault extraction using a WMR RMS ant-tracking volume as a guide as well as manual fault extraction was used to create a stereonet diagram defining the orientation of faulting in the area. The stereonet diagram indicates the major trend of fracturing and faulting in the region trends $15^{\circ}$ to $30^{\circ}$, figure 14 . The principal trend of faulting being perpendicular to the most compressive stress yields a paleo $\sigma_{1}$ orientation during Marcellus Alleghenian deformation of $105^{\circ}$ to $120^{\circ}$.

Log data was used in hard calibrations against gamma ray and density to discern the significance of the WMR RMS attribute. Four wells were utilized for this process and were analyzed individually, however; the small number of data points, approximately 10 , per individual well was deemed statistically insignificant. These wells were then compiled to increase the number of samples used in the correlation and to minimize the non-uniqueness of the results. Correlation coefficients range from 0.0025 to to 0.46 in figure 15 . Such a large discrepancy in the correlations calls for an advanced observation of the data, for further explanation reference section 5.5. 


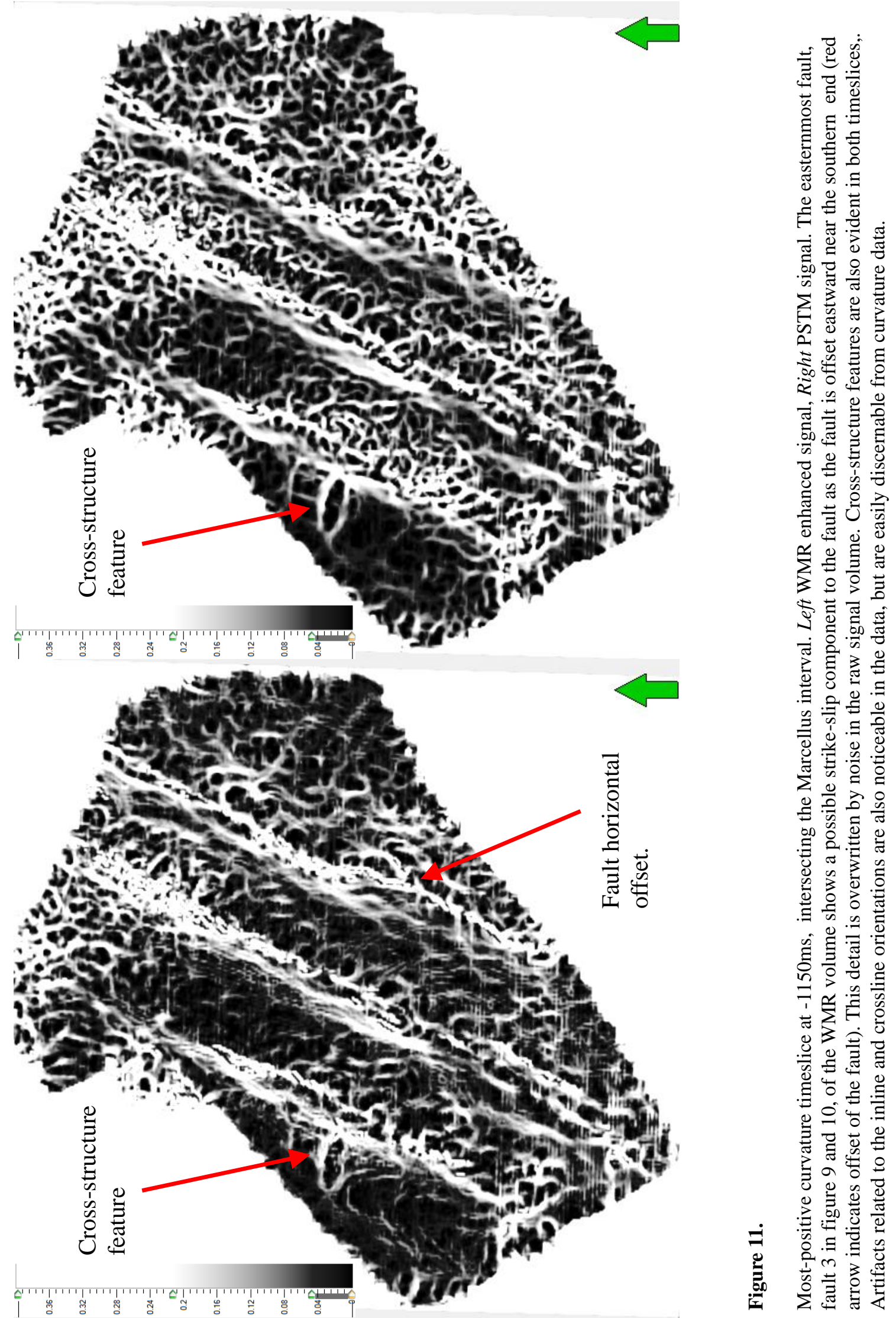




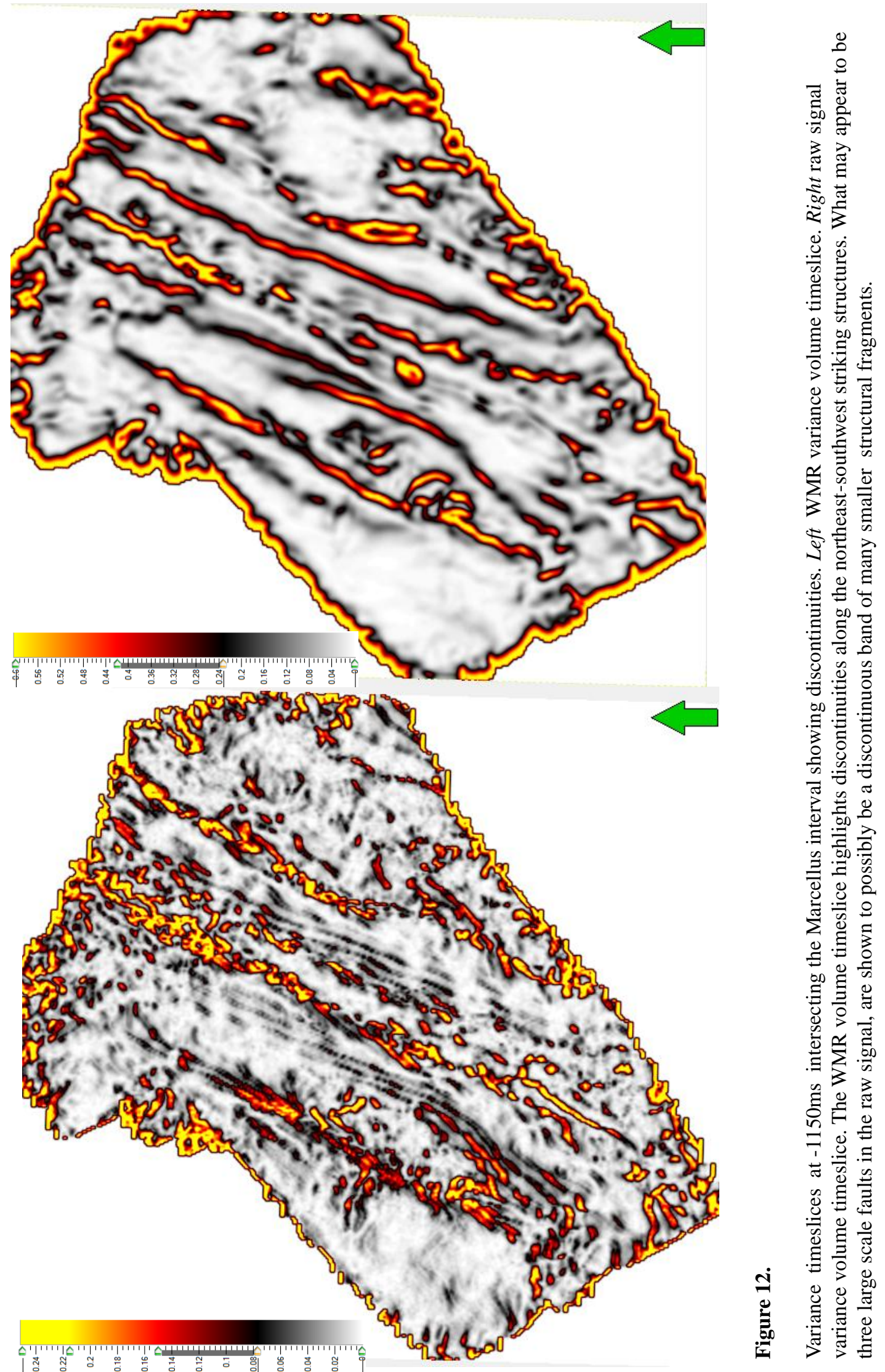



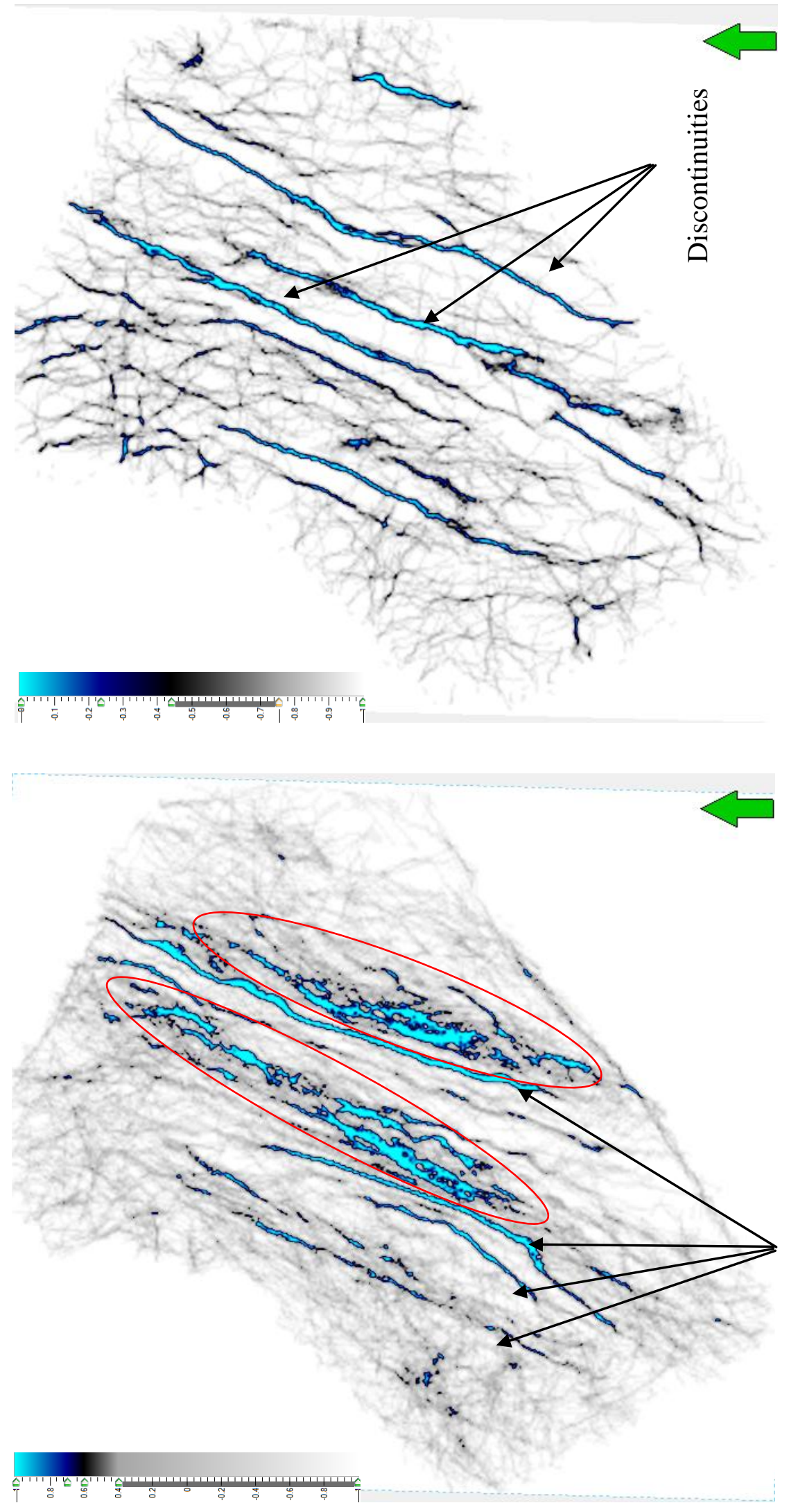

•

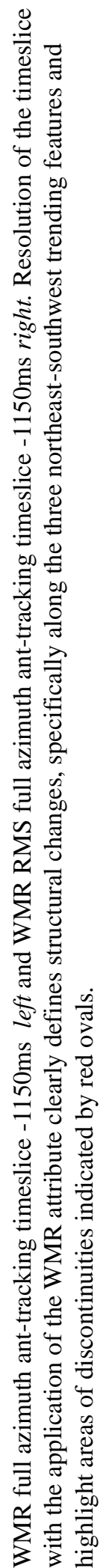




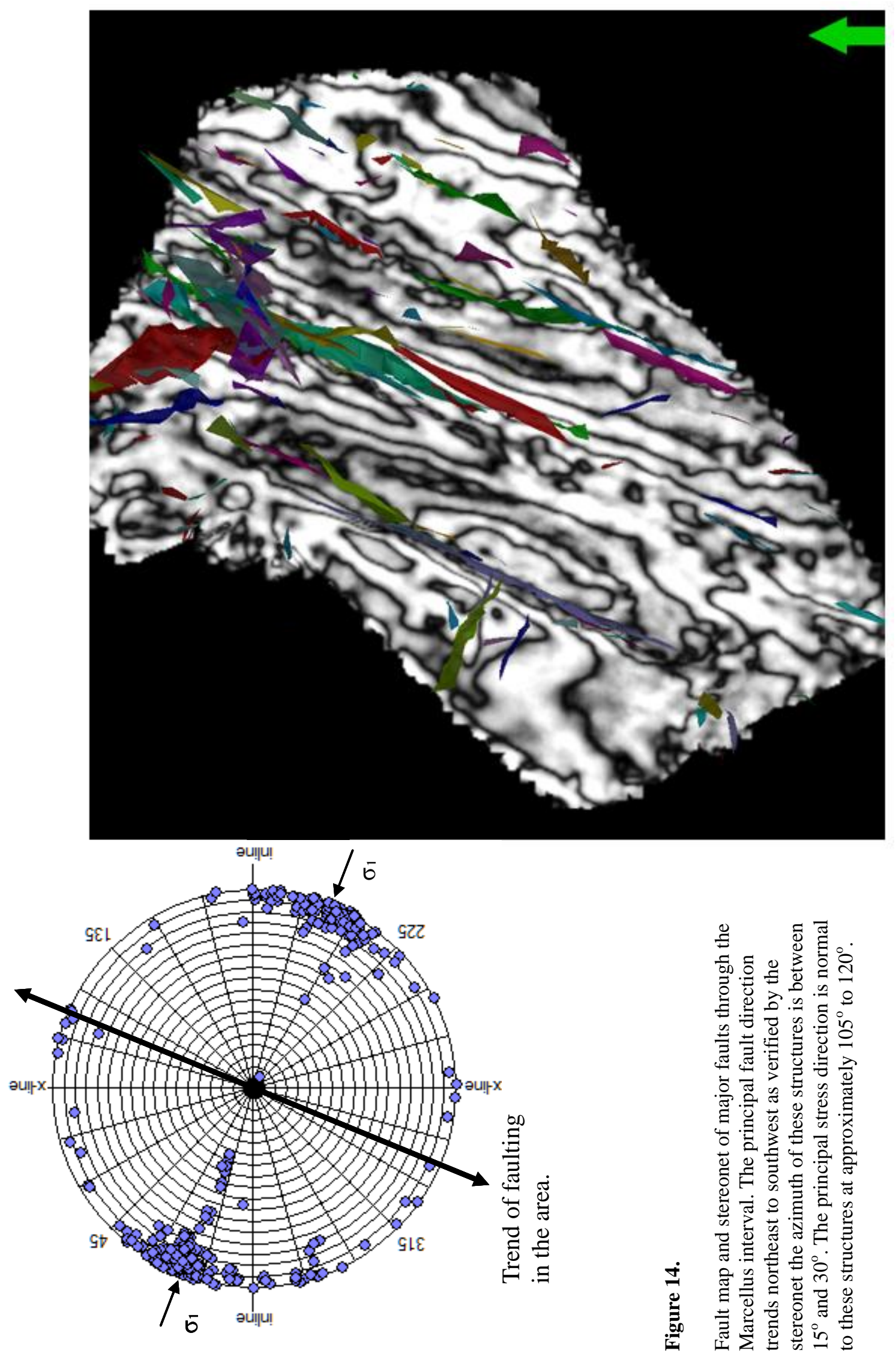



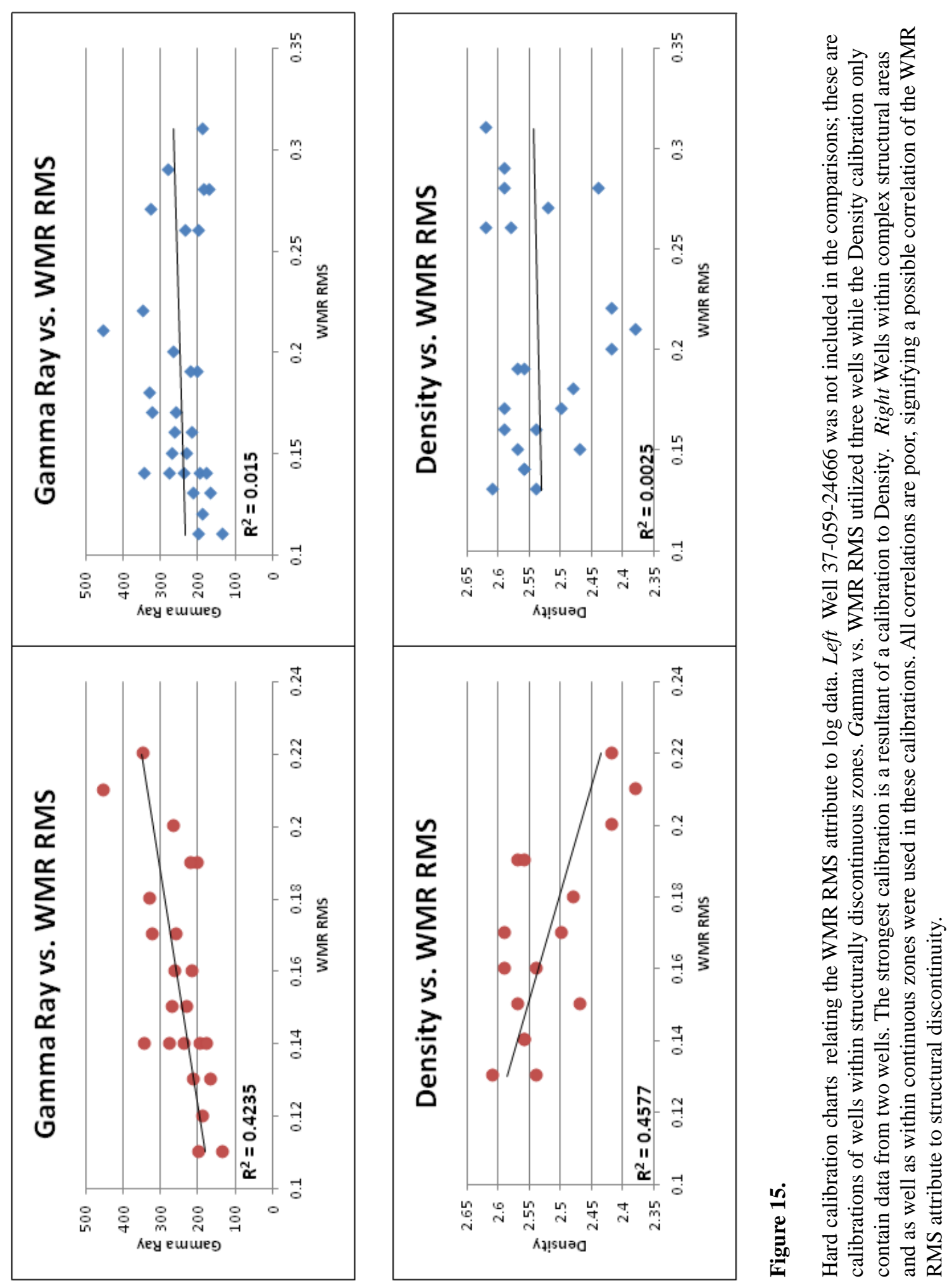


\section{Chapter 5: Interpretations}

Most evident within the study region is the existence of three major northeast-trending reverse faults. Anticlinal and synclinal features accompany these major faults resulting in a complex spatial and temporal relationship of the folds and faults. Furthermore, these faults are not solitary, rather they are compounded with many smaller faults or a combination of deeper and shallower faults (figure 16).

Basement structures perhaps, play a vital role in the propagation and evolution of overlying structural features. Derived from Rome Trough initiated extension, these faults experienced episodes of compression and decompression resulting at times in fault reactivation which may be expressed as younger features in overlying rock intervals. These faults tend to exist in accordance with the opposing thrust orientations in Devonian age rocks. Figure 16, is representative of deep seeded faulting likely inducing deformation of overlying intervals and directly impacting geometries of subsurface structure.

Reactivation either with normal or thrust geometries may have induced strain on the overlying rocks of Silurian and Devonian age resulting in the creation of a high strain region which may explain the overlying fault complexities. Attributing to these geometries, Middle and Late Silurian and Early and Middle Devonian stratigraphy has higher shale content and thus multiple zones of weakness. Here the formation of small-scale detachement intervals has been interpreted, figure 16. At these planes of weakness, the occurrence of varying fault dip direction occurs more frequently, creating a saw-tooth geometry of thrust faults interpreted in figure 16.

\subsection{Structural Fabric Development}

In spite of being located in the foreland of a west-vergent thrust belt, motion is primarily east-vergent along detachment fault planes (figure 16). These backthrusting faults are evident throughout the study area, however; their existence in conjunction with east dipping thrust faults in a 'saw-tooth' pattern is intriguing. A variety of modes of deformation may be the cause for the opposing west and east-vergent movements: the existence of a transition zone where east-vergent thrusts due to continental collision are opposed by the Laurentian plate resulting in both westvergent and east-vergent thrusting; strain accumulation and mechanical failure in overlying brittle units due to underlying west-vergent movement along a Salina detachment; or this may occur in response to basin inversion. Additionally, the notion of a wedge/flake model, similar to 
Oxburgh (1972) and Price (1986), may define the inverse faulting direction, east to west dipping, along a larger predicted west dipping fault. This model proposes a highly strain resistant rock volume being either stationary or having some movement either in opposition or coincidence with collision of plates during orogenesis.

It is proposed a moving volume may develop in two manners. First, movement of the robust volume may be of a different velocity than surrounding rocks allowing for the formation of east dipping faults along the hinterland side and west dipping faults caused by the displacement of the wedge or flake volume forelandward. Additionally, movement of this proposed wedge/flake may be episodic, occurring from the initiation of a tectonic pulse of a certain magnitude, deriving from shallow thrusts or deeper seeded basement reinitiation.

In a west-vergent thrust system, movement about the stationary volume would result in strain accumulation along the upper and lower perimeter of the volume. East dipping thrust faults may develop above the eastern edge of the flake, while strain accumulation beneath the eastern edge would deflect stratigraphic intervals down resulting in a east-vergent thrust along the inside of the wedge. Ductile deformation is interpreted to occur within each of these proposed deformation mechanisms as rock area must be preserved at the fore and aft regions of the wedge/flake volume. A diagram of this model and its possible geometry in the seismic data is given in figure 17.

Additionally, cross-strike-discontinuities are observed from the 3D seismic and seismic attribute data. In map view, a series of cross-structural features are observed to cross the major northeast-trending folds and faults, specifically in the Marcellus interval. Oblique-to-strike patterns may be related to basement structure reactivation and block movement, but may alternatively be associated with detached thrust tectonics as conjugate shear planes as they strike at approximately $30^{\circ}$ to the principal stress direction and dip at high angles (figure 18). Complex structural deformation geometries in the lower intervals (Ordovician) may be indicative of the lateral movement along cross-structural lineaments, see figure 4 for a map of proposed lineaments. 


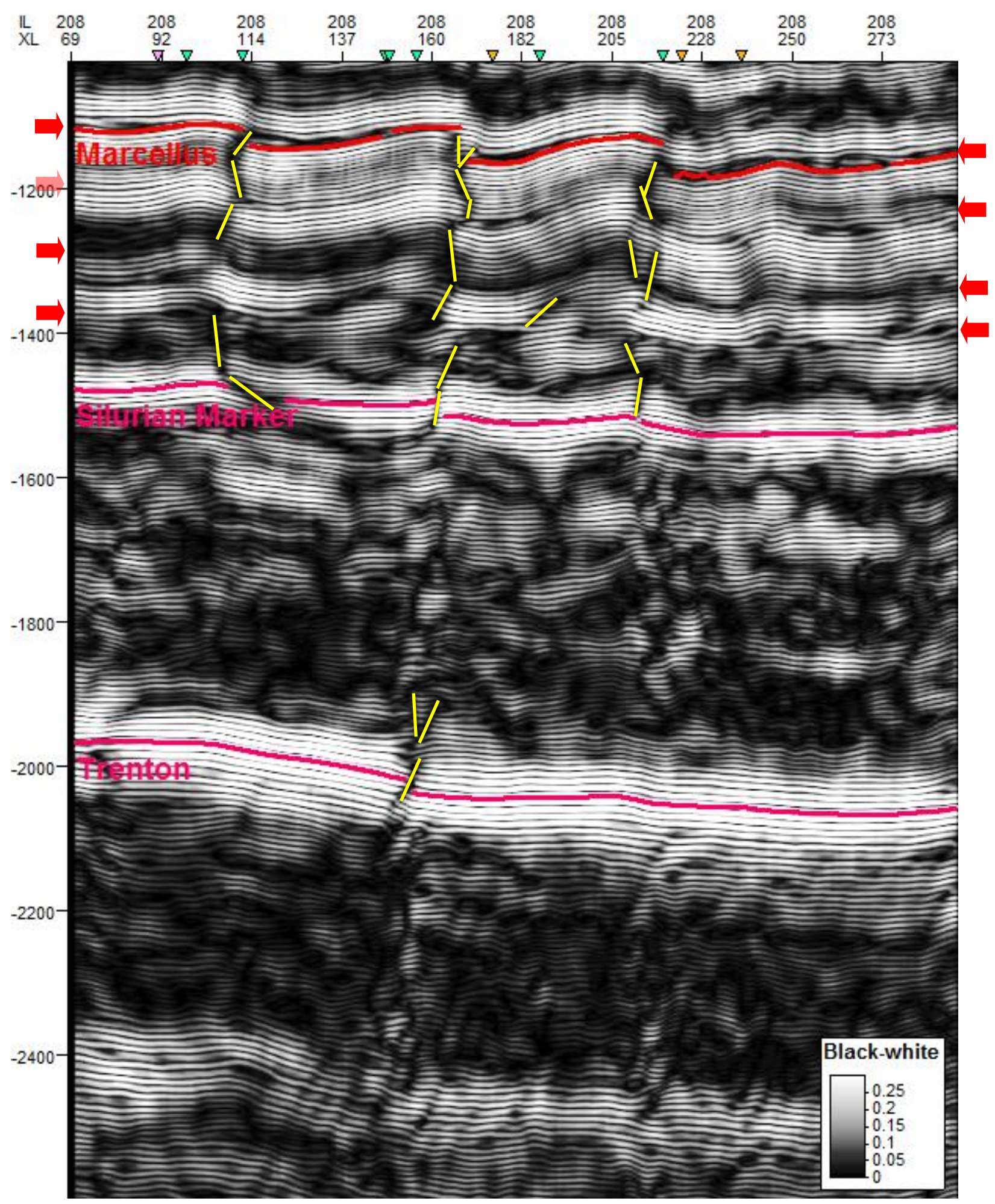

Figure 16.

Inline 208 in the WMR volume showing the Early Odovician through Middle Devonian structure. Interpreted faulting is highlighted by yellow lines and red arrows represent interpreted detachment locations. Between the Silurian marker and the Marcellus interval an opposing thrust geometry is present which may stem from underlying basement faulting highlighted by teal arrows. 


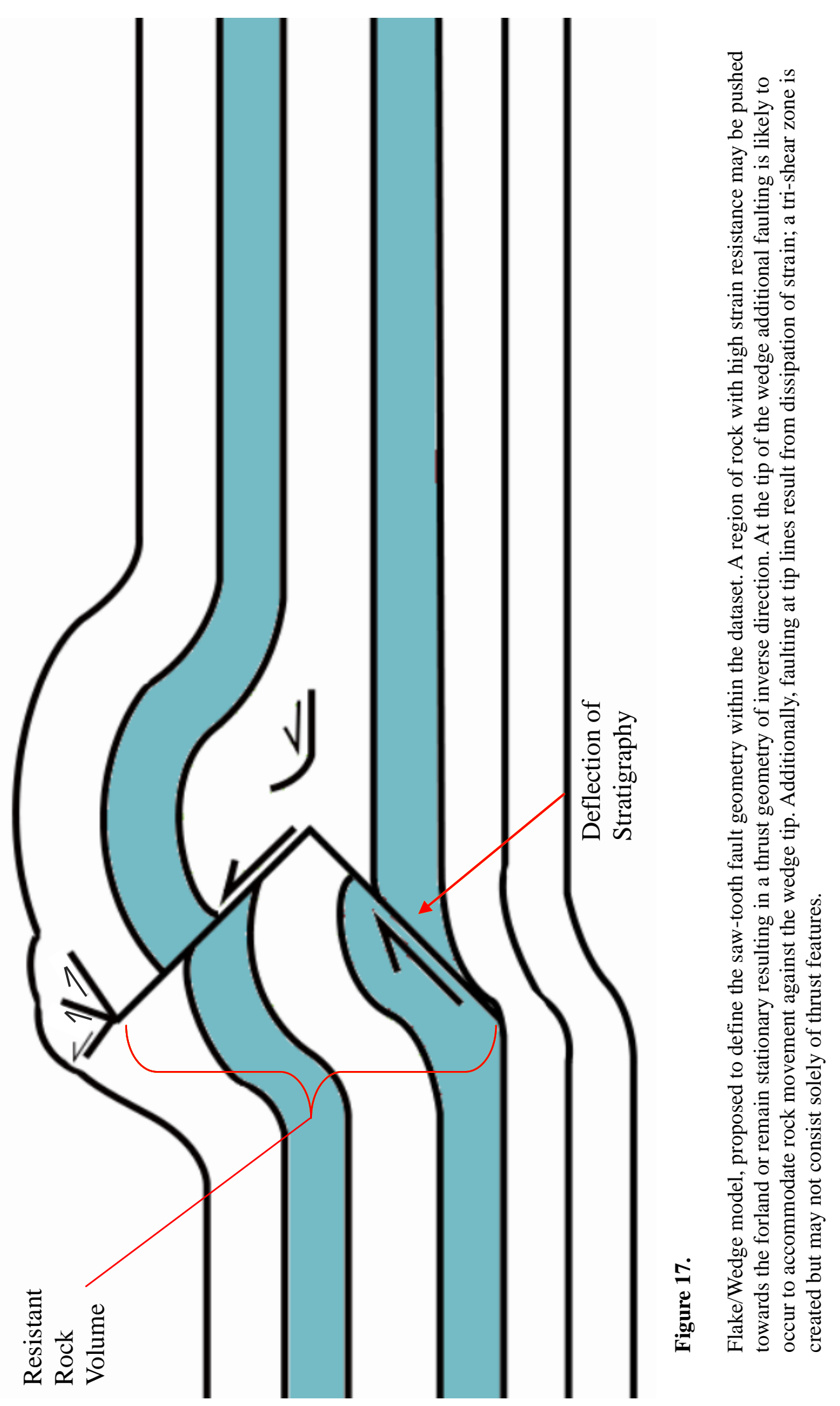




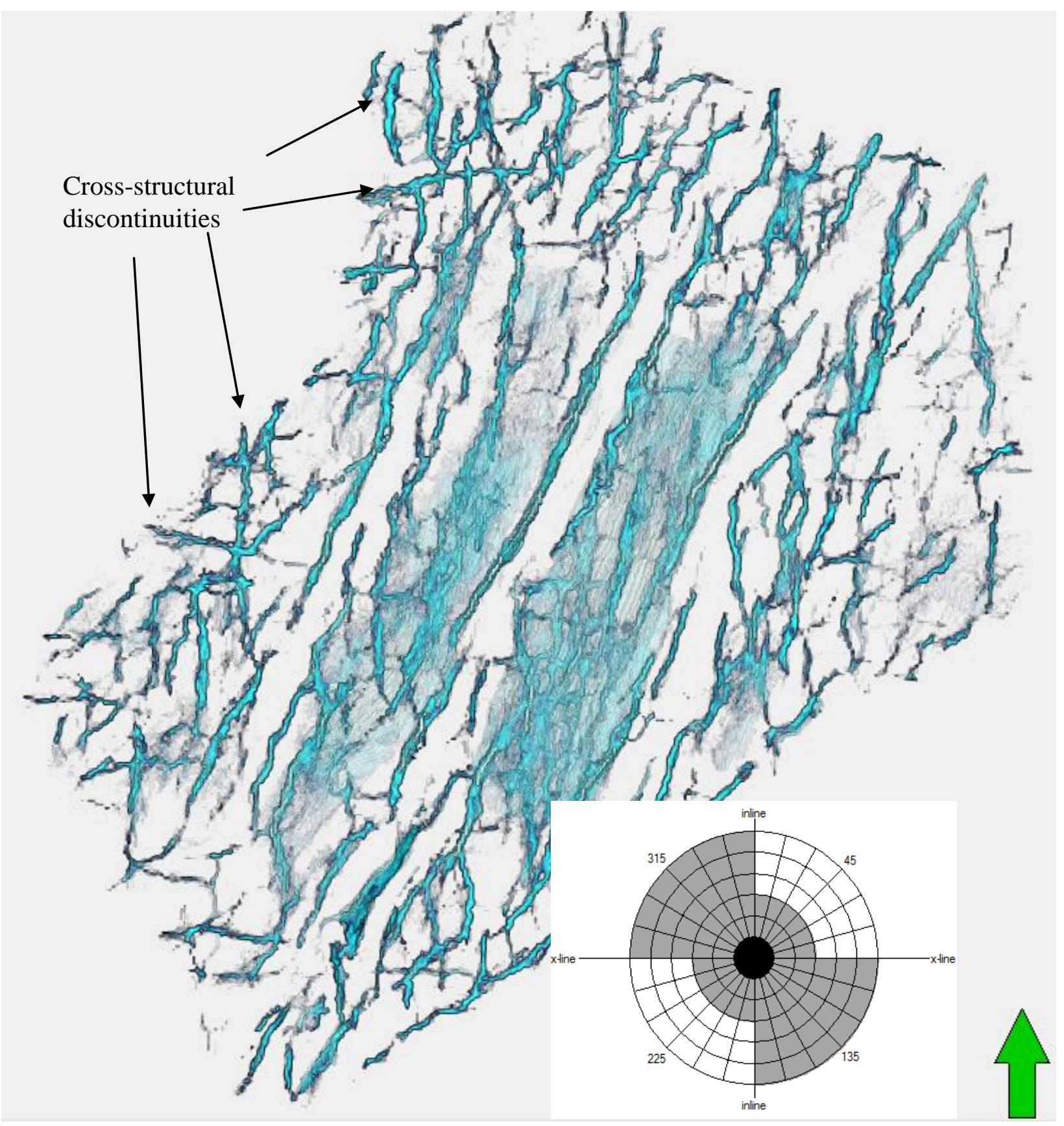

Figure 18.

WMR RMS ant-tracked volume of the Marcellus interval. Cross-structural discontinuities and oblique to strike features are readily observable and are marked by arrows in the ant-tracked interval volume. These features may indicate conjugate shearing or alternatively may indicate an en echelon pattern. Ant-tracking was subject to azimuth search bounds between 0 and 90 degrees and from 180 to 270 degrees. 


\subsection{Fundamental Interpretations}

\subsubsection{Regional Dip}

The overall dip of the study area is southwest into basin; this dip is recognized in intervals as deep as the basement and through the Silurian, see figure 16. Basinward dipping may be a result of multiple episodes of subsidence, but is more likely defined by the reactivation of Rome Trough normal faults possibly in relation to decompression post-orogenisis. These periods of decompression likely occurred during quiescent periods between collisional orogenic events and may be the cause for east-vergent thrust faults associated with the Silurian Salina detachment and vertical offset in deeper intervals, see figure 16.

\subsubsection{Differential Contraction}

Strike-slip characteristics may be indicative of transpressional tectonics due to differential contraction. Alternatively, these strike-slip faults may be indicative of tear faulting due to differential gravitational sliding. The central and the easternmost faults bend along their trend providing further evidence for probable differential contraction. However, figure 18 clearly identify the components of strike-slip associated with compressional events, having a nearly $60^{\circ}$ orientation in relation to the direction of the maximum principle stress. The existence of additional northeast/southwest trending faults not visible in other maps may be an indication of an imbricate fan geometry, which may apply to the overall structure of the study area.

\subsubsection{Gravitational Sliding}

An indication of gravitational sliding is derived from observations of the westernmost major fault, fault 1 in figures 8 through 10 . Unlike other faults in the study area, this fault does not traverse the entire data set; rather it begins abruptly in the southern region and decays in the northern region. This is possibly due to non-uniform strain in the region and may also be an indication of differential contraction. Upon creating three cross-sections along the fault and observing an anticline associated with the fault, it is evident that the fault likely propagated laterally with strain decaying out toward the tip points, (figure 19). Additionally, this geometry may be indicative of increasing strain along the fault from the tip line to the center of the thrust fault.

\subsubsection{Basement structures}

Basement structures play an important role in defining the reservoir as they may transmit through thousands of feet of rock, resulting in a direct relationship to the Marcellus structure. 
Figure 20, a series of cross sections at inline 198, clearly depicts faults propagating upsection through the Marcellus interval. It is likely reactivation of basement faults acted to create basin inversion in a transpressional environment. Although inversion is likely, a complete reversal of offset in basement normal faulting may not have taken place. Alternatively and additionally, it is possible collisional decompressional extension post orogensis may have resulted in the reactivation of or creation of Rome Trough normal faults, which may be directly related interval dips from the basement through the Silurian (figure 16 and 20). Moreover, this possible reactivation of extension may have retracted offset created by inversion of the basement. 

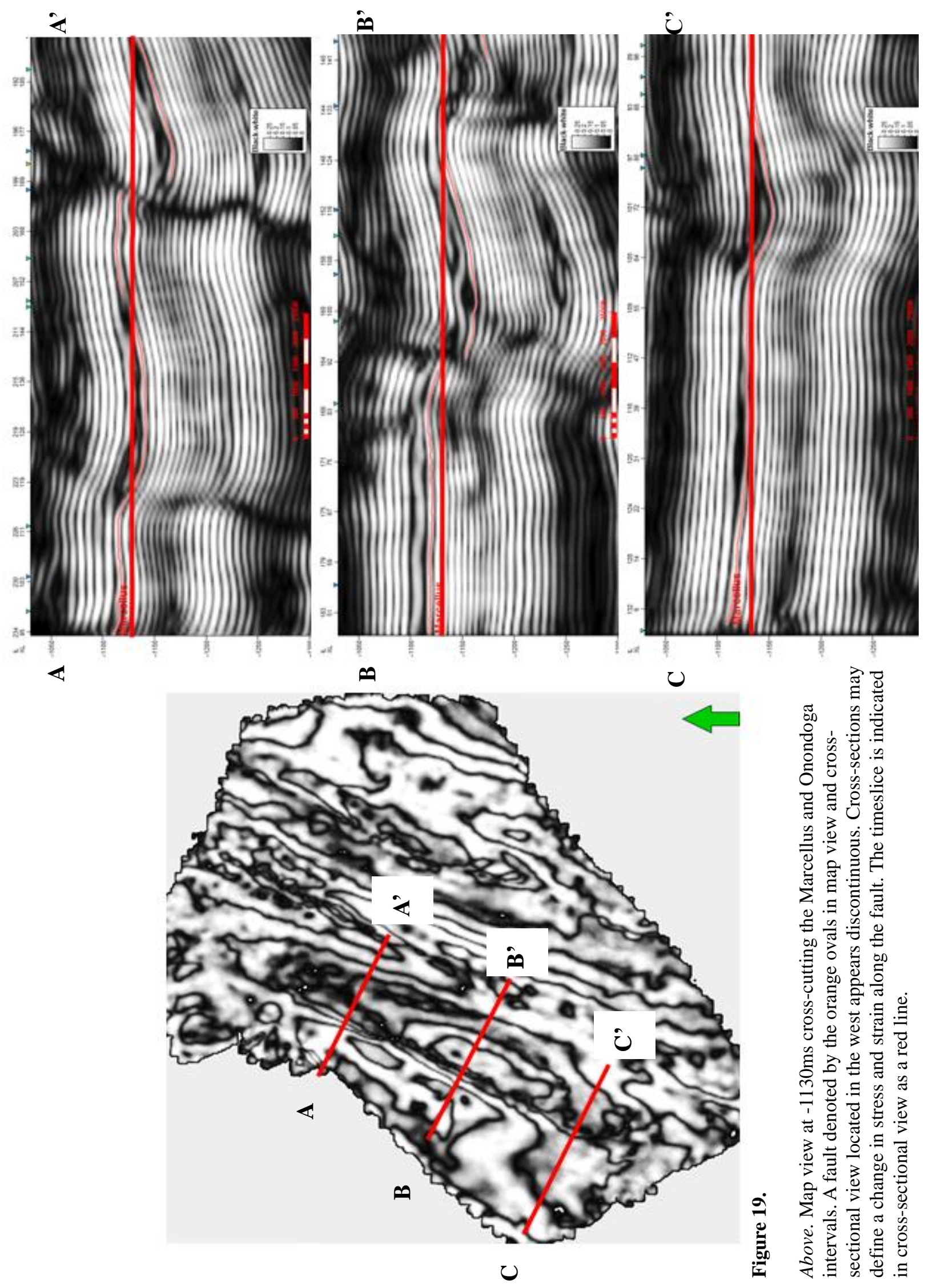


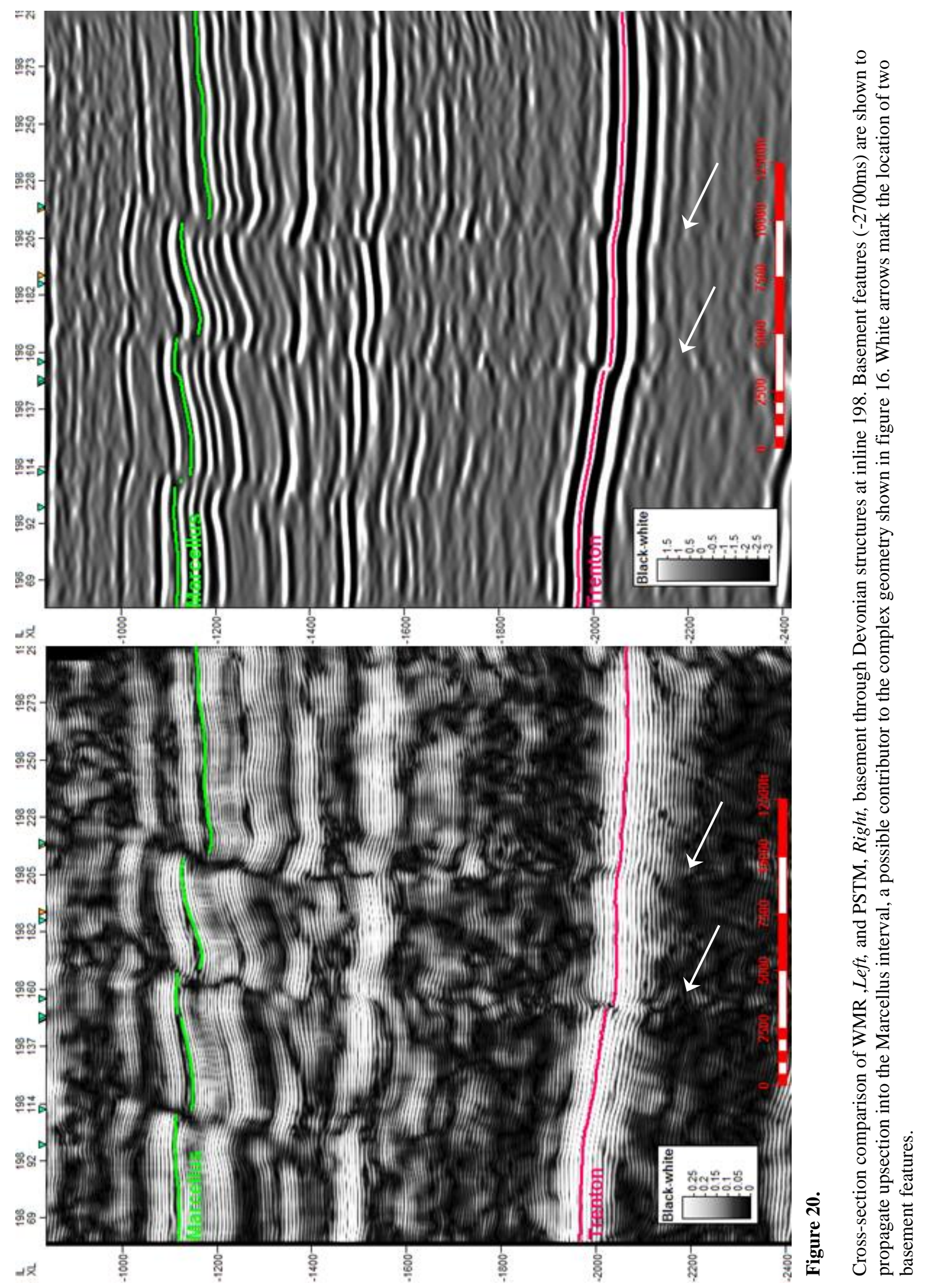




\subsection{Structural Interpretation in the Detachment Intervals}

In addition to the detachments indicated in the statigraphic section of figure 1 marked by black arrows, two more detachment zones are interpreted between the Marcellus and Salina; figure 16 highlights these interpreted detachment zones, signified by red arrows. These detachments, as well as, underlying zones of detachment are crucial pieces in the structural framework as propagation faults, pop-up folds, structural wedges and fault-bend folds initiate within the detachment interval. Moreover, the potential hydrocarbon play is affected by these modes of deformation as they directly impact the nature of different fractures (e.g., tensile vs. shear fractures) and thus rock properties such as, porosity and permeability. Density and resistivity may vary at these locations and may be suggestive of lithologic changes and fracture infill.

Complex deformation and strain heterogeneity within the Marcellus/Mahantango interval may cause potential drilling problems or may lead to increased production in the reservoir system. This detachment is continuously visible throughout the study area and is revealing of the structural complexity of the play, as small-scale detachment fault features plague the interval, figure 21. This detachment is most continuous within the Mahantango interval, but occasionally reaches the Marcellus interval. Figure 26, highlights the strength and location of this detachment in the Mahantango and Marcellus intervals as a function of the continuity of the rock. At these intervals bright areas (red/orange) are suggestive of mechanical failure resulting in discontinuities such as faults and fractures and may either be geohazards or target areas. Detachments at greater depth are more discontinuous across the study area and reveal inconspicuous small-scale structures. Nevertheless, these detachments play a critical role in the development of structures up section.

\subsubsection{Interpretations of the Silurian Salina Detachment}

Faults derived from the Silurian Salina are seldom isolated thrusts; it is more often the case these thrusts are accompanied by others forming an array pattern and imbricate fan geometries. These thrust likely occur as a combination of the wedge/flake and rock flow along a Salina detachment. In either instance, formations of folds occur as a result of deformation and conservation of area and/or as a function of fault-induced folding. Fault dip direction varies in some of these complex fault systems, further justifying the wedge/flake model interpretation of 
the region. The pattern of varying fault propagation matches well with the wedge/flake model in figure 17; this was not however the only active structural mechanism within the basin.

\subsubsection{Interpretations of the Marcellus/Mahantango Detachment}

It is unlikely offset at the Marcellus/Mahantango detachment is caused by syndepositional faulting as displacement along the Marcellus/Mahantango detachment appears to be west-vergent, figure 24. It is also improbable that a regional dip as observed in intervals downsection (e.g. the Silurian and below) affects the detachment at this interval. Rather it is probable both the wedge/flake model and localized gravity-induced sliding were coincidental in forming the apparent west-vergent motion along the Marcellus/Mahantanogo detachment. Figure 24 may confirm at least part of this idea as folding and faulting occur at the location of anticlinal uplift and may be the result of localized gravity- induced sliding.

However, at some locations, (figure 21) east-vergent thrusts form along the proposed west-vergent detachment interval. This may be explained by the wedge/flake model as the tip of the wedge may be located near or within the detachment interval allowing for west-vergent movement and the formation of west dipping thrust faults (figure 17). Nevertheless, the model may not apply in regions where the observation of a west dipping fault appears to oppose the west-vergent motion. Here, an alternative mode of deformation or a complex network of deformational styles is likely the cause for apparent counter motion thrusts and oppositely dipping intervals between the Devonian and older intervals as can be seen in figure 16. 


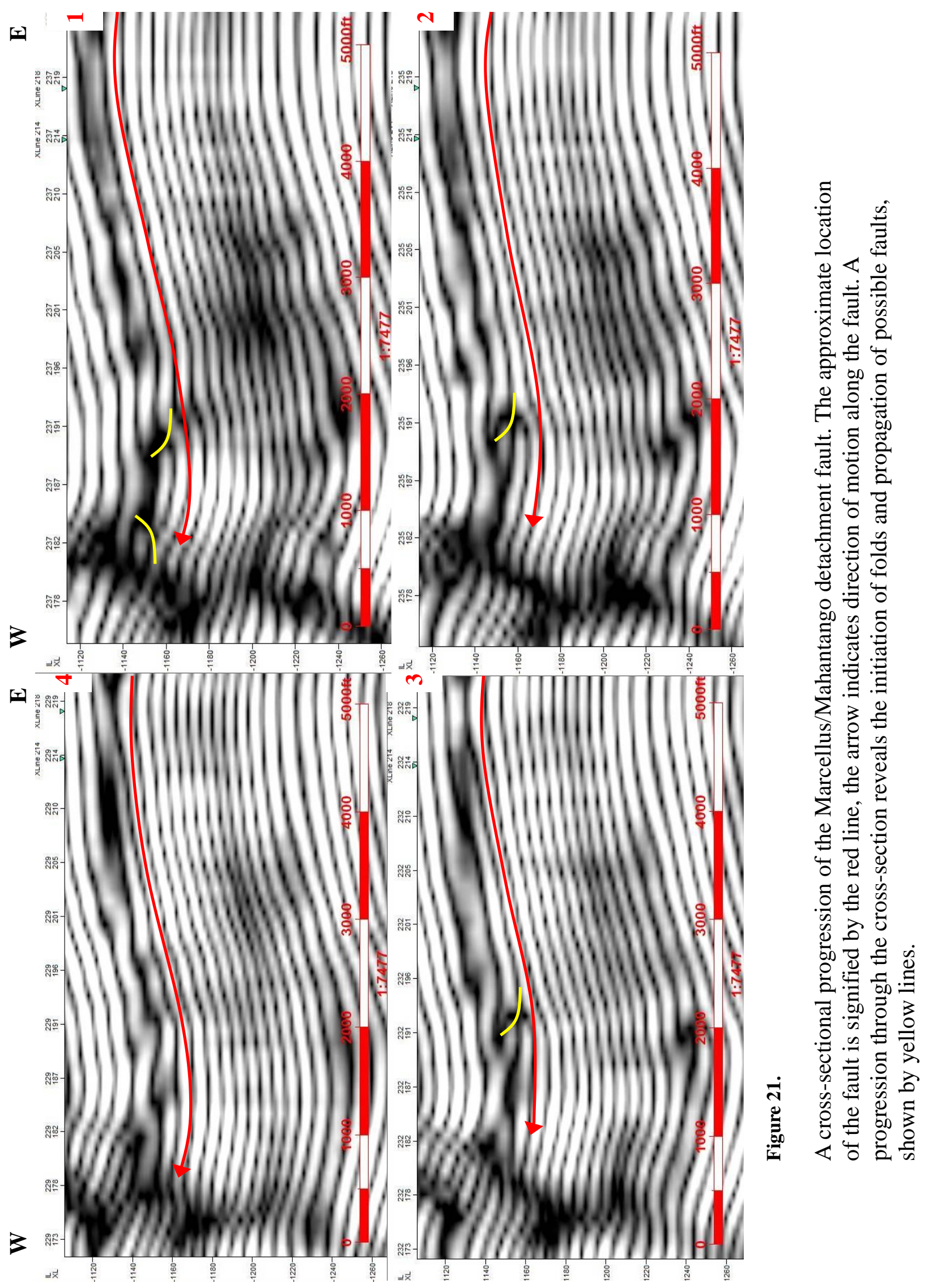




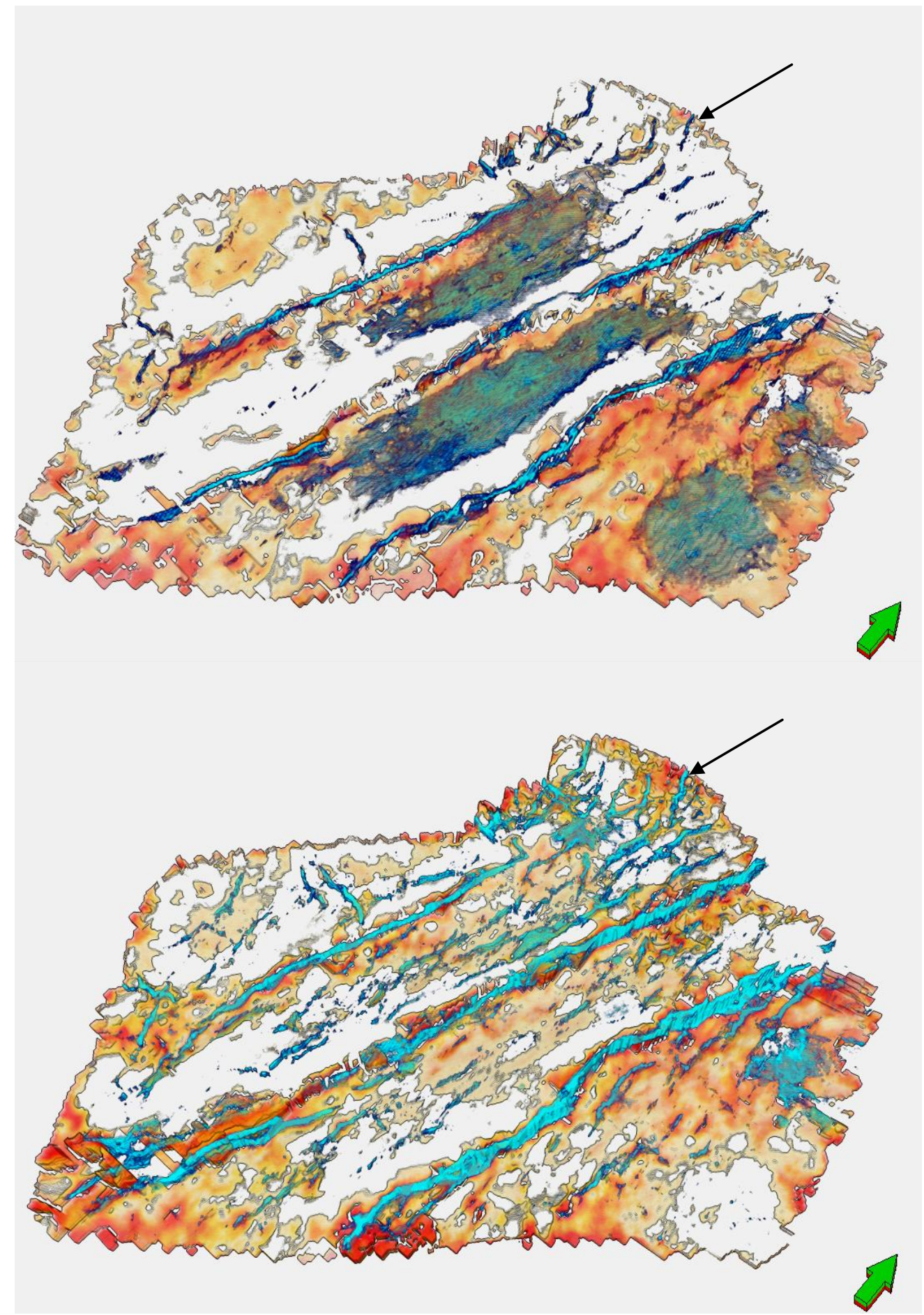

Figure 22.

WMR RMS Marcellus interval overlay on WMR RMS ant-track Marcellus interval. Blue defines discontinuities in structure, the large volumes of blue indicate fracture intensity or small scale faulting at the Marcellus/Mahantango detachment. The orange and red are the WMR RMS attribute, indicating zones of rock property change possibly due to structural discontinuities. Overlapping of the attributes may indicate zones for well placement. 


\subsection{Complex Structural Interpretations}

\subsubsection{Tri-shear}

Tri-shear zones originate from tiplines of thrust faults as the faults propagate upsection. These regions of strain dissipation may result in areas of local fractures in overlying intervals as strain transmission may not impose a large enough displacement on the overlying beds to allow for fault propagation, but may induce fracturing due to local shear strain and flexure of beds. Vertical offset may also be present in a region of tri-shear. These zones are easily recognizable in the WMR attribute data, yet other attributes such as curvature, ant-tracking and variance, fail to delineate entirely or clearly the complexities of this feature. Figure 23, depicts the WMR attribute's ability to discern structural features. Figure 23 part b and c respectively, represent the combination of the WMR RMS and WMR volume and the RMS ant-tracking and WMR volume.

\subsubsection{Fractures}

Fracturing was likely induced from a variety of localized strain regimes present during and after Marcellus deposition. Interference of regional and local stresses over time caused overprinting in faults and likely fractures and may be in part cause for the creation of complex fracture networks of different generation in this area. Initially, regional stress acted in a transpressional nature and likely resulted in the formation of joint sets within the Marcellus interval parallel to the most compressive stress. Additionally, Engelder et al. (2009) discussed joint formation as a product of natural hydraulic fracturing deriving from the maturation of organic material; infill of these features is likely as examples from the field indicate calcite and quartz filled fractures and veins, figure 24. It is highly probable joint sets of this nature, trending both northwest-southeast and northeast-southwest, are overprinted by later fracturing to form farreaching fracture networks.

Open fractures may also form as networks along and normal to the hinge and axis of a fold, either anticline or syncline. Consequently, pre-existing fractures and joint sets are uplifted and downthown along folds and faults in this thrust system resulting in overprinting and possibly re-opening of joint sets and fractures. Buried fractures and joints within the deposited interval at this time were likely infilled by minerals, creating planes of weakness within the rock interval. Surficial fractures and joints created additional accommodation space for organic or clastic deposition. 
Figure 25 represents the WMR RMS ant-tracking volume over the Marcellus interval. These regions are discontinuous and presumably fractured due to the fault propagation from Mahantango to Marcellus of the Mahantango/Marcellus detachment fault. The strongest discontinuities are in the northeast region (figures 22 and 25) of the survey area where the Marcellus/Mahantango detachment changes depth and increases the influence on the Marcellus interval, by paralleling the interpreted interval top or incising the interval causing folding and fold-induced fracturing. Discontinuities due to the intra-interval detachment are shown in figure 26. The detachment is more continuous within the Mahantango interval and at times develops in the Marcellus interval.

\subsubsection{Cross-Strike Structural Lineaments}

Cross-structural lineaments were originally presumed as conjugate shear faults due to regional contraction. Further investigation reveals these features are due to a transpressional environment and possibly rotation of a fault block bordered by structural lineaments, figure 4 . En-echelon pattrens are evident in figure 18 and 22 at both the Mahantango and Marcellus interval, revealing the transpression within the basin. These features are associated with the westernmost fault in the Mahantango interval; the easternmost and central faults in the Marcellus interval develop this geometry as well.

Visible throughout both intervals, a southeast striking feature extends from the data bounds to the westernmost fault. This feature may be related to the Greene County Lineament, figure 4, as the elements of the lineament may extend for an unknown distance from the interpreted location and this observed structure follows the same trend. Furthermore, this feature is corresponding to the principal stress direction which parallels the northwest-southeast trending lineaments in the region. It is unlikely this feature is conjugate in nature as it is nearly normal to the thrust fault and parallel to the principal stress direction.

\subsection{Observations and Interpretations of Attribute Calibrations}

The WMR RMS attribute was calibrated to well log data in order to define what, if any, rock property the attribute signifies. The results, shown in figure 15, indicate no definitive corollary for the attribute though correlations are higher at areas of discontinuity than areas of non-fractured rocks. This is expected as the WMR attribute is designed to enhance structural discontinuity and would likely be more effective for calibration to a strain log. Additionally, an 
explanation for poor correlations at continuous rock intervals and good correlations within discontinuous intervals may be found upon analysis of the correlations.

Calibrations at discontinuous regions yield good correlations to density and gamma ray; here a negative correlation is defined for density and positive correlation for gamma ray. This may be indicative of concretions in fracture rich zones as carbonate concretions would yield a higher density and likely a lower gamma ray value resulting in the inverse relationship of density and gamma ray within these regions. This notion is strengthened by the correlation of density to WMR RMS as lower values $\sim 0$ to 0.2 of the WMR attribute and thus WMR RMS attribute are indicative of discontinuous regions which may contain concretions, see section 3.2.2 Attributes, Waveform Model Regression. Calibrations at continuous or less fractured intervals do not result in this inverse relationship. Instead gamma ray and density each have a very poor, nearly zero, positive correlation to the WMR RMS attribute, see figure 15. 
W

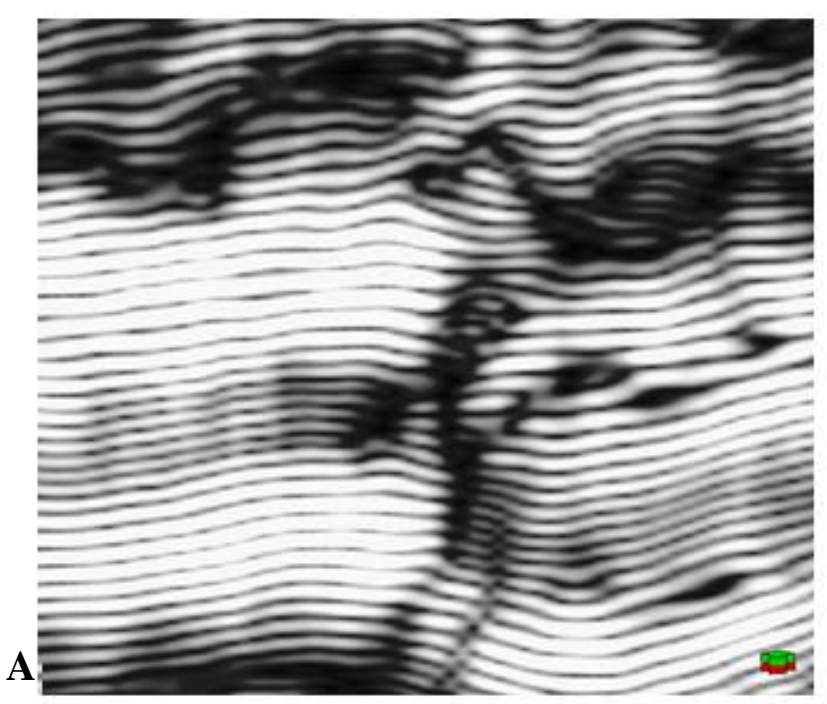

$\mathbf{E}$

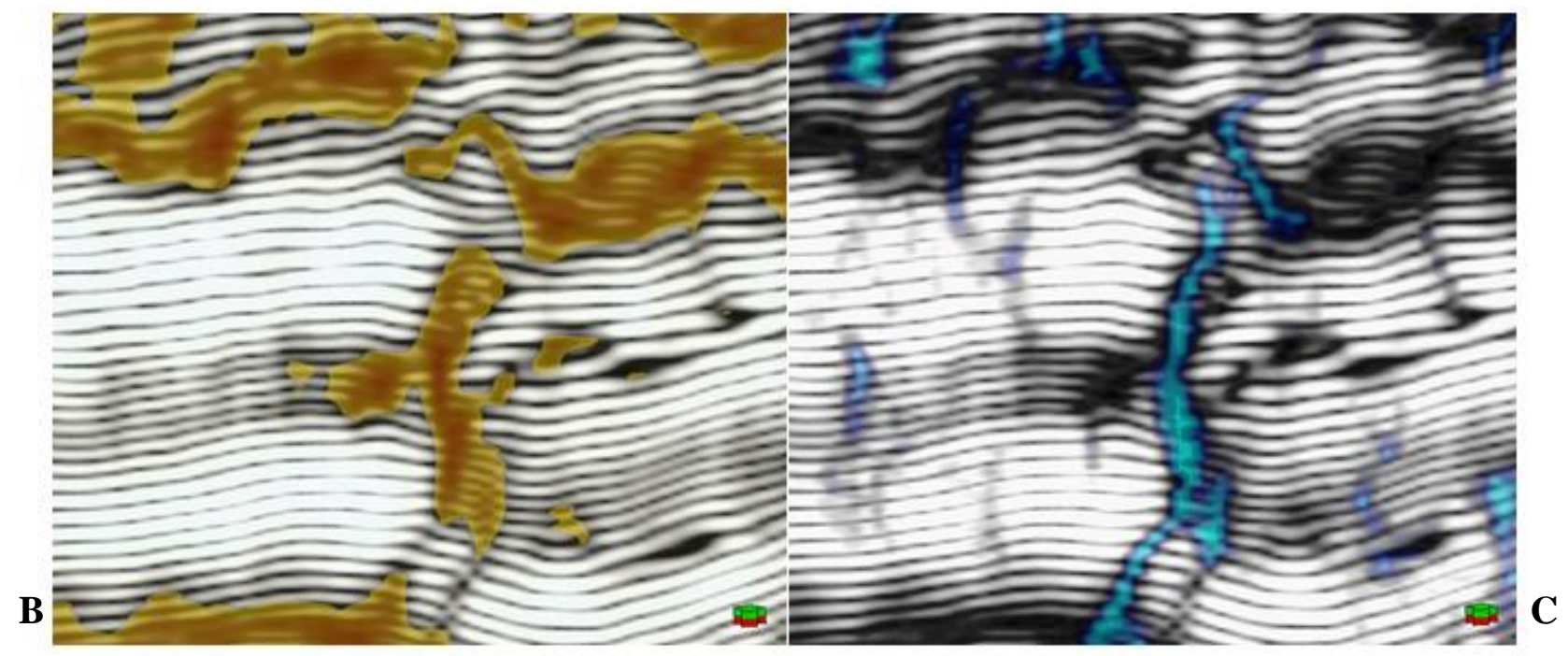

Figure 23.

Representation of the WMR enhanced volume's ability to increase the resolution of structural features $\mathbf{A}$. WMR RMS overlay on A indicating the attribute may define structural discontinuity or rock property change, $\mathbf{B}$. The WMR RMS ant tracking method, $\mathbf{C}$, further highlights structural discontinuity and may be used to define areas of fractures and faults. 


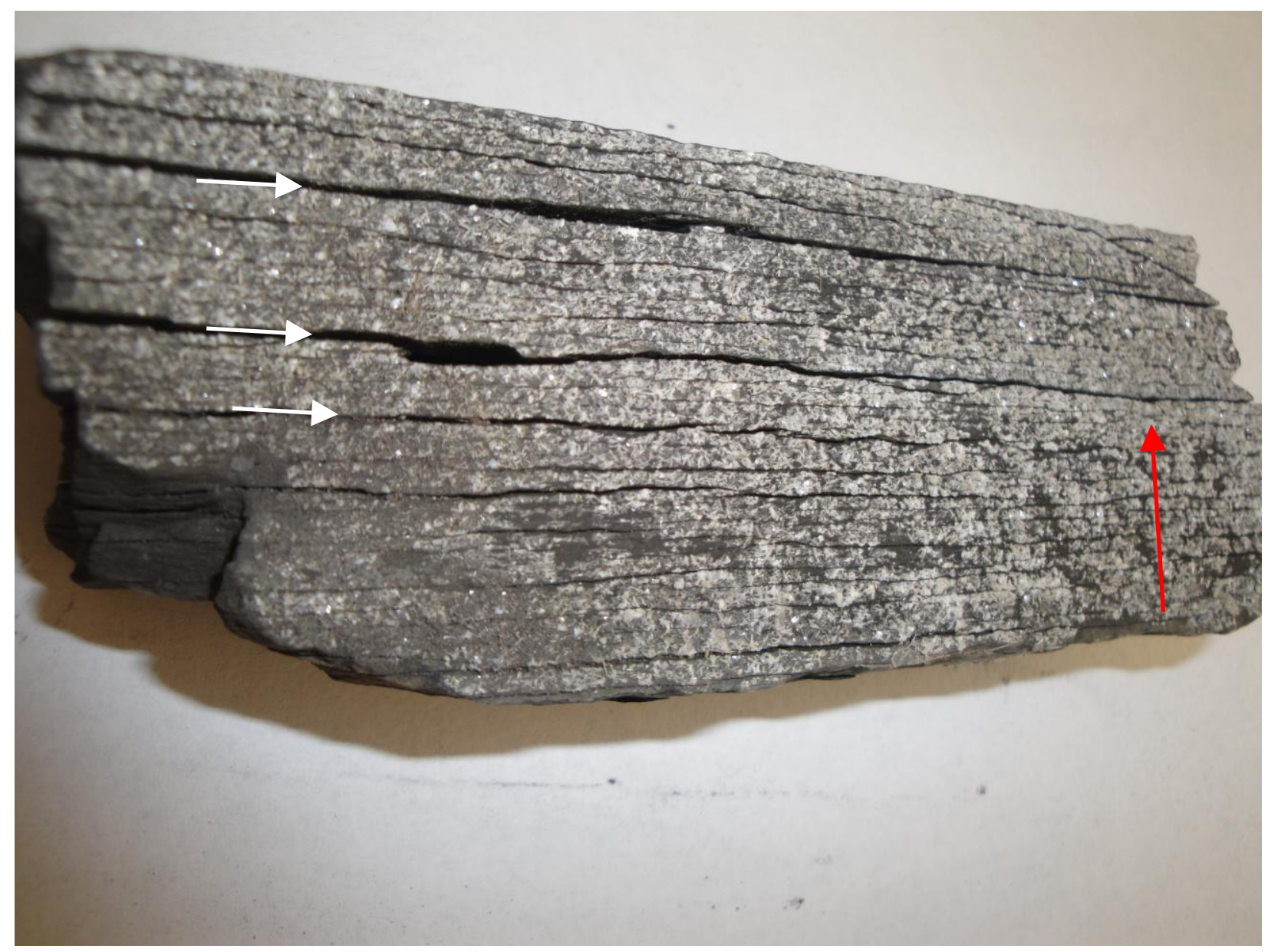

Figure 24.

Marcellus shale field sample photograph. White arrows indicate that the Marcellus interval can be easily broken into thin sheets. This sample also displays calcite infill of fractures, denoted by the red arrow, found along the face of this sample in some secitons. Zones of weakness are created at regions of infill and may be utilized in the production of hydrocarbons from the Marcellus play. 


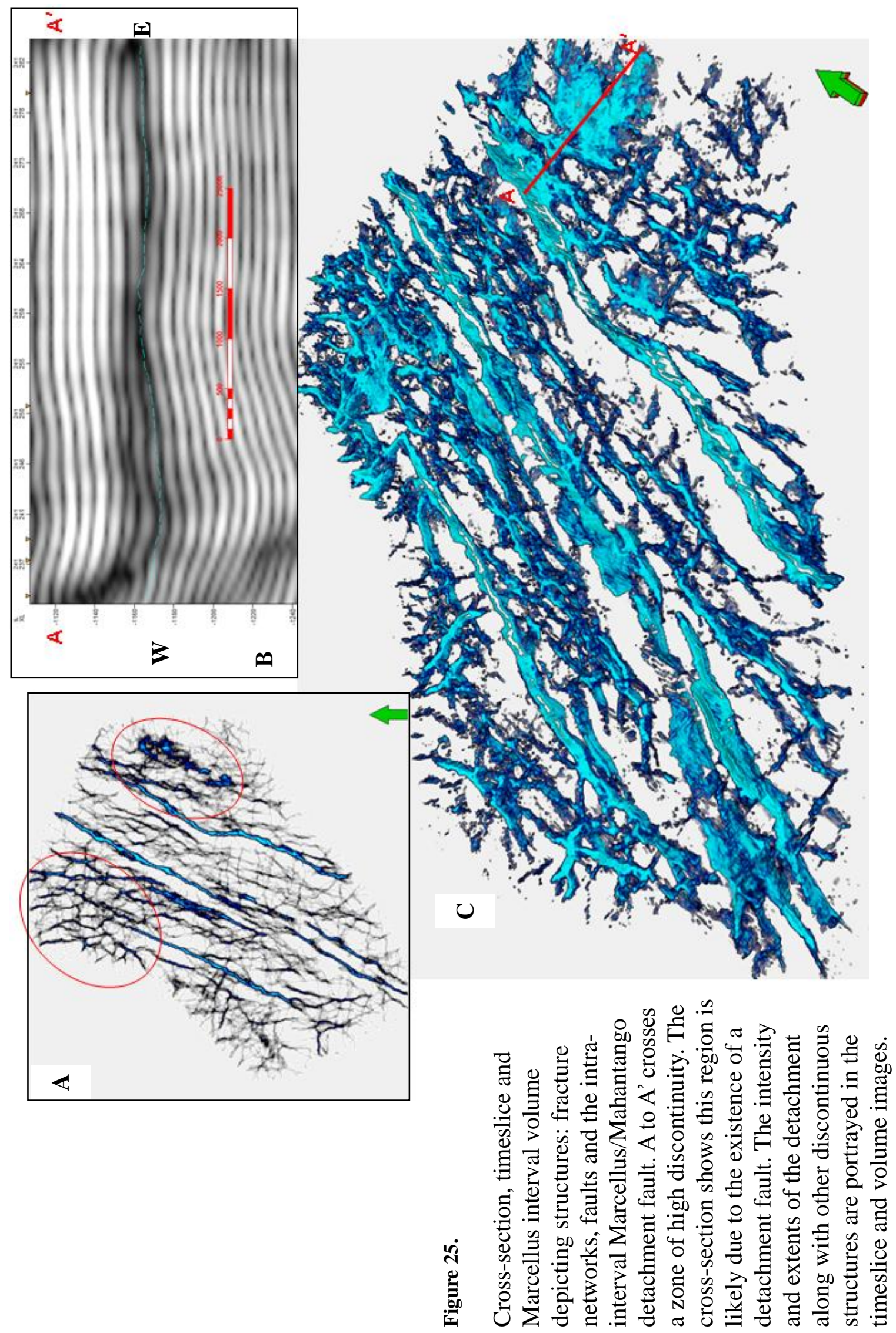




\section{Chapter 6: Hydrocarbon Implications}

Unconventional reservoirs are typified by rock intervals having low porosity and permeability. These reservoirs, unlike conventional reservoirs are, also characterized by rock intervals that act as both source and trap. To overcome this induced hydraulic fracturing within these intervals is utilized. Artificially fracking creates migration pathways for absorbed hydrocarbons to escape. To enhance the effects and projection of these artificial fractures, horizontal wells are typically drilled perpendicular to the present day maximum principal stress. Therefore, understanding the subsurface in terms of fracture orientation and fracture networks and defining the continuity of fault and folds is important to the placement and production of wells.

Implications for hydrocarbon exploration and production are derived from: location and intensity of fracture networks; continuity of fault propagation, thrusts and detachments; and significance of attribute calibrations to the reservoir interval. Well placement may avoid or target zones of high fracture intensity, though this decision will vary from company to company, mapping of these locations is vitally important. Faulting and fault continuity are also important to the hydrocarbon system as extensional faulting or faulting with a strike-slip component may lead to complications and a leaky interval. Figures 26 and 30 are representations of rock discontinuity through the application of ant-tracking to the WMR RMS attribute; additionally figure 26 contains an overlay of the WMR RMS attribute. The blue, representing discontinuity, is indicative of faulting and possibly fracturing within the Marcellus interval. These maps are important for delineating zones of possible communication, represented here by red circles, as communication may lead to drilling and fracking issues. Faulting, folding and presumably faulting rooted in the Marcellus/Mahantango detachment are the likely cause for this discontinuity; the cross-section A-A' highlights the detachment and associated discontinuity in the data.

Figure 26 further illustrates the effects of the detachment fault. Here, the westernmost and central fault clusters, responsible for the vertical offset and visualized as independent large scale thrust features, at the Marcellus interval are likely transpressional as en echelon faults accompany them in the north and partially through the central part of the study area. These faults are possible conduits for hydrocarbon and other fluid migration; communication between wells is likely at these regions. 
In the northeast corner of the data set a discontinuous region is accompanied by low valued WMR RMS, as the WMR RMS attribute may be indicative of a change in rock properties at a structural change. This would be ideal for the placement of a well in the Marcellus; however, the fracture network is correlative to intra-interval detachment faulting. As the detachment fault wanders from the Mahantango to the Marcellus it is unadvised to drill the Marcellus at this location as hydraulic fracking may cause migration into the detachment zone.

The location of zones of tri-shear may also be targets for drilling as the tiplines of faults associated with the dissipation of strain may produce small-scale fracture networks. These networks are likely interconnected as the horizontal displacement of tiplines is at times only a few hundred feet apart. This principle may also be applied in other areas where a fault tip line nears the Marcellus interval.

Tops of intervals in anticlines and the base of intervals in synclines may provide good target locations as open fractures have a tendency to form here. Open fractures are likely zones of higher porosity and permeability, presumable due to a fracture network across the folded region. Staying in section is typically challenging when horizontal wells are drilled; thus, staying within a few tens of feet from the planned target well path may not be possible along an entire well. However, if this is possible it may result in increased production, provided fracking of the interval does extend beyond its bounds.

If unit repetition exists, by duplexes or from the flake model (figure 17), drilling may benefit from this overlap as it may allow for multiple levels of wells within the target interval, reference figure 21. Here a single pad may drill the same interval in two separate vertical levels, reducing the cost of moving a well pad and purchasing or leasing land for the location of a well pad as this method increases the number of wells that may be drilled from a single pad location. Though this may not apply directly to the study area, there may be regions where this does apply in areas of the basin where a greater horizontal displacement has occurred. 


\section{Chaper 7: Conclusions and Future Work}

\subsection{Conclusions}

The static phase waveform model regression (WMR) attribute effectively increases the dominant frequency and improve the signal-to-noise ratio of traditional seismic amplitude data, resulting in an increased resolution and visualization of subsurface structures. Application of this attribute helped define the structural framework in the study region; moreover, this attribute would be a vital asset in other exploration projects. Calibration of the WMR volume further enhances the understanding of structural and the mechanical complexities of the hydrocarbon reservoirs.

The WMR RMS attribute was used in a hard calibration to rock properties. As the WMR attribute functions as an indicator of waveform likeness, high WMR RMS values occur at strongly continuous zones while discontinuous regions are related to low RMS values and thus dissimilar waveform character. Though the trend of the WMR RMS mirrors structural discontinuity, it is unlikely indicative of the larger structural network. Rather the WMR RMS attribute signifies rock property variance due to structural discontinuity associated with subtle structures; therefore defining possible zones of intricate small-scale fracture networks may be completed through the application and calibration of the WMR attribute.

\subsection{Future Work}

Locally small-scale structural features are made visible within the $25 \mathrm{mi}^{2} 3 \mathrm{D}$ dataset and are vital in defining the local structural framework. However, the regional framework of the basin has not yet been revealed. Therefore, future studies at both the local and regional scale are important to understand the overall structural framework of the basin. This region may then be more clearly defined through a broader analysis of the area as the use of supplementary 3D datasets and possibly 2D lines may yield a more robust picture of the framework of the basin. Additionally, an in depth analysis and calibration of the WMR attribute, specifically with the RMS volume in the depth domain, to log data may yield a conclusive structural corollary. Should this occur, the WMR attribute may be studied in other regions of the basement to further define the corollary rock property for future exploration and production projects. It is furthermore suggested a field study be completed to increase the understanding of the complexities of intrainterval detachment folds. This study may be complemented by a petrophysical analysis focused 
on the comparison of intervals of continuity and discontinuity; it may also be valuable to retrieve well $\log$ data to complete this correlation.

\subsection{Final Thoughts}

\subsubsection{Wedge/Flake Thrust Model}

This model may be a preferred model for defining the study area as it effectively reasons the occurrences of accordion-thrusts. It is not however the writer's interpretation the only mode of deformation observed within the region. It is alternatively suggested this model plays a critical role in the deformation of the Marcellus interval and works in conjunction with a number of other deformational mechanisms as the Appalachian Basin region was subject to many episodes of tectonism developing different structural styles.

\subsubsection{Seismic Imaging in the Appalachian Basin}

The future of the basin will likely become more friendly toward seismic data acquisition and interpretation, specifically 3D seismic as it allows for an in depth view of structural features pertinent to hydrocarbon location and extraction. The application of new attributes and their interpretation are presumably the next step beyond data acquisition. Attributes, particularly those derived from waveform analysis; provide an improved visualization for subtle structural and stratigraphic features. Waveform model regression in this study portrays the usefulness of such attributes in defining the structural complexities of the subsurface. This attribute is proficient in discerning small-scale features located intra-interval which may then be calibrated to log properties to develop a further understanding of the relationship between rock characteristics and attribute values. Calibrations of this nature may be used basin wide or within a local area. New attributes may be instrumental in developing advanced interpretations of the subsurface provided the interpreter understands their geologic implications. 


\section{Bibliography}

Blakey, R.C. (2010). www2.nau.edu/rcb7/nam.html.

Boswell, R. (1988). Stratigraphic expression of basement fault zones in northern West Virginia. Geological Society of America, 100, 1988-1998.

Boyce, M. L. (2010). Sub-surface stratigraphy and petrophysical analysis of the Middle Devonian interval of the central Appalachian basin; West Virginia and Southwest Pennsylvania. (Doctoral Dissertation). Retrieved from ProQuest. 3448208.

Castle, J. W. (2001). Foreland-basin sequence response to collisional tectonism. Geological Society of America Bulletin, 11(7), 801-812.

Chopra, S. and Marfurt, K. J. (2010). Integration of coherence and volumetric curvature images. The Leading Edge, 29, 9, 1092-1107.

Curtis, J. B., and Faure, G. (1997). Accumulation of organic matter in the Rome trough of the Appalachian basin and its subsequent thermal history. American Association of Petroleum Geologist Bulletin, 81(3) 424-437.

Edmonds, C. A. (2004). Natural gas exploration associated with fracture systems in Alleghenian thrust faults in the Greenbrier Formation, southern West Virginia. (Masters Defense). Retrieved from ProQuest. 1424912.

Engelder, T. (2004). Tectonic implications drawn from differences in the surface morphology on two joint sets in the Appalachian Valley and Ridge, Virginia. Geology, 32(5), 43-416.

Engelder, T. and Whitaker, A. (2006). Early jointing in coal and black shale: Evidence for an Appalachian-wide stress field as a prelude to the Alleghanian orogeny. Geology, 34(7), 581584.

Engelder, T., Lash, G. G., and Uzcategui, R. S. (2009). Joint sets that enhance production from Middle and Upper Devonian gas shales of the Appalachian Basin. Association of Petroleum Geologists Bulletin, 93 (7), 857-889.

Faill, R. T. (1997). A geologic history of the north-central Appalachians; part 1, orogenesis from the Mesoproterozic through the Taconic Orogeny. American Journal of Science, 297, 551619.

Gao, D., and Shumaker, R. C. (1996). Subsurface geology of the Warfield structures in southwestern West Virginia: Implications for tectonic deformation and hydrocarbon 
exploration in the Central Appalachian Basin. American Association of Petroleum Geologists Bulletin, 80(8), 1242-1261.

Gao, D., Shumaker, R. C., and Wilson, T. H. (2000). Along-axis segmentation and growth history of the Rome Trough in the central Appalachian basin. American Association of Petroleum Geologists Bulletin, 84(1), 75-99.

Gao, D. (2002). Seismic textures aid exploration: Offshore, 62 (9), 65.

Gao, D. (2004). Texture model regression for effective feature discrimination: Application to seismic facies visualization and interpretation. Geophysics, 69. 958-967.

Gold, D.P., Alexander, S. S., Cakir, R., Doden, A. G., and Root, S. I. (2005). Precambrian basement map of the Appalachian basin and Piedmont province in Pennsylvania. Pennsylvania Geological Survey, Portion of Open-File General Geology (OFGG) Report OFGG 05-01.0.

Harrison, M. J., Marshak, S., and McBride, J. H. (2004). The Lackawanna synclinorium, Pennsylvania: A salt-collapse structure, partially modified by thin-skinned folding. Geological Society of America Bulletin, 116(11/12), 1499-1514.

Karabinos, P., Samson, S. D., Hepburn, J. C., and Stoll, H. M. (1998). Taconic orogeny in the New England Appalachians: Collision between Laurentia and the Shelburne Falls arc. Geology, 26, 215-218.

King, E. R., and Zietz, I. (1978). The New York-Alabama lineament: Geophysical evidence for a major crustal break in the basement beneath the Appalachian Basin. Geology, 6, 312-318.

Kulander, B. R., and Dean, S. L. (1986).Structure and tectonics of central and southern Appalachian Valley and Ridge and Plateau Provinces, West Virginia and Virginia. American Association of Petroleum Geologists Bulletin, 70(11), 1674-1684.

Kulander, C. S. and Ryder, R. T. (2005). Regional seismic lines across the Rome Trough and Allegheny Plateau of northern West Virginia, western Maryland, and southwestern Pennsylvania. U.S. Geological Survey, Geologic Investigations Series, I-2791.

Lash, G. G., and Engelder, T. (2011). Thickness trends and sequence stratigraphy of the Middle Devonian Marcellus Formation, Appalachian Basin: Implications for Acadian foreland basin evolution. American Association of Petroleum Geologists Bulletin, 95(1), 61-103. 
Lewis, J. E., McDowell, R. R., Avary, K. L., and Carter, K. M. (2009). Characterization of the Helderberg Group as a geologic seal for $\mathrm{CO}_{2}$ sequestration. Environmental Geosciences, 16(4), 201-210.

Marfurt, K. J., Kirlin, R. L., Farmer, S. L., and Bahorich, Michael S. (1998). 3-D seismic attributes using a semblance-based coherency algorithm. Geophysics, 63(4), 1150-1165.

McDaniel, B. A. (2006). Subsurface stratigraphy and depositional controls on Late DevonianEarly Mississippian sediments in southwest Pennsylvania. (Masters Defense). Retrieved from ProQuest. 1440964.

Oxburgh, E. R. (1972). Flake tectonics and continental collision. Nature, 239, 202-204.

Park, H., Barbeau, D. L., Jr., Rickenbaker, A., Bachmann-Krug, D., and Gehrels, G. (2010).Application of foreland basin detrital-zircon geochronology to the reconstruction of the southern and central Appalachian orogeny. The Journal of Geology, 118, 23-44.

Parrish, J. B. and Lavin, P. M. (1982). Tectonic model for kimberlite emplacement in the Appalachian Plateau of Pennsylvania. Geology, 10, 344-347.

Price, R. A. (1986). The southeastern Canadian Cordillera: Thrust faulting, tectonic wedging, and delamination of the lithosphere. Journal of Structural Geology, 8(3-4), 239-254.

Shumaker, R.C. (1996). Structural history of the Appalachian basin, in Roen, J.B., and Walker, B.J., eds., The atlas of major Appalachian gas plays. West Virginia Geological and Economic Survey Publication, 25, 8-22.

Shumaker, R. C. and Wilson, T. H. (1996). Basement structure of the Appalachian foreland in West Virginia: Its style and effect on sedimentation. GSA Special Papers 308, 139-155.

Stetltenpohl, M. G., Zietz, I., Horton, J. W. Jr., and Daniels, D. L. (2010). New York-Alabama lineament: A buried right-slip fault bordering the Appalachians and mid-continent North America. Geology, 38(6), 571-574.

Taylor, S. R., and Toksöv, M. N. (1982). Crust and upper-mantle velocity structure in the Appalachian orogenic belt: Implications for tectonic evolution. Geological Society of America Bulletin, 93, 315-329.

VerStraeten, C. A. (2004). K-bentonites, volcanic ash preservation, and implications for Early to Middle Devonian volcanism in the Acadian orogeny, eastern North America. Geologic Society of America Bulletin, 116(3/4), 474-489. 
Wilson, T. H. (2000). Seismic evaluation of differential tectonic subsidence, contraction, and loading in an interior basin. American Association of Petroleum Geologists Bulletin, 84(3), 376-398.

Yan, J., Zhao, Z., Wen, X., Tang, X. R., and Gu, W. (2011). Interpretation and detection of fracture zones by multi seismic attributes. [Abstract]. Society of Exploration Geophysicists Expanded Abstracts, 30,1784-1788.

Yanni, A. (2010). Subsurface stratigraphy and petrophysical analysis of the Middle Devonian interval, including the Marcellus shale, of the central Appalachian basin; northwestern Pennsylvania. (Masters Defense). Retrieved from ProQuest. 1490256.

Zeng, H. (2010). Geologic significance of anomalous instantaneous frequency. Geophysics, 75(3), 23-30. 


\section{APPENDIX I}

Hard-Calibrations Workflow:

i. Open a well section window

i. Display the wells of interest along with well tops

ii. Record the thickness of intervals

ii. Open an interpretation window.

i. Select an inline that intersects the well of interest.

ii. Display the well of interest and attribute to be inverted

a. Display well tops

b. Count the number of voxels (samples) within the interval of interest

c. Divide the thickness (step I) by the number of voxels

1. Record thickness defined by each voxel

d. Record the attribute value for each voxel

iii. Return to the well section window

i. Define the log of interest

ii. Right-click on log of interest in input pane

iii. Record the log values over the interval of interest

iv. Open a mathematical software (i.e. Excel)

i. Create two columns

a. Voxel (sample) value

b. Log value

ii. Run a crossplot of these values for each inline/crossline

a. Do a linear regression

iii. Record this value and interpret 


\title{
Appendix II
}

Seismic Processing Workflow:

\author{
Preprocessing \\ Geometry Assignment \\ Elevation Statics \\ Refraction Statics - if required \\ Phase/Amplitude Calibrate Dynamite and Vibroseis Sources \\ Trace Edit \\ Spherical Divergence Correction \\ Noise Attenuation (Weinman's Proprietary LNX3D) \\ Fast Track Volume for First Pass Statics and Velocities: \\ Single Trace Deconvolution \\ Single Trace Gain Corrections \\ (these processes are for statics and velocity analysis only - will not be on final volume.) \\ Preliminary Velocity Analysis (1 mi grid) \\ Surface Consistent Residual Statics \\ Surface Consistent Amplitude Compensation \\ Surface Consistent Deconvolution \\ Velocity Analysis ( $1 / 2 \mathrm{mi}$ grid) \\ Surface Consistent Residual Statics (minimum 2 iterations with velocity analysis) \\ Spectral Enhancement (as required) \\ Amplitude Balance (as required) \\ CMP Trim Statics (not applied to azimuthal gathers) \\ $\rightarrow$ Break Flow for Input to Imaging \\ Post-Stack Imaging: \\ Offset Bin and Regularization \\ Dip Moveout \\ Velocity Update \\ Stack \\ Interpolate to $110 \times 110$ \\ Kirchhoff Curved Ray Time Migration \\ Gain/Signal Enhancement (as required) \\ Pre-Stack Imaging: \\ Migration Velocity Analysis on Target Output Locations (min $1 \mathrm{mi}$ grid) \\ Kirchhoff Curved Ray Prestack Time Migration \\ (Aperture determined by testing, up to 15,000 ft) \\ Velocity Analysis (1/2 mi grid) \\ Gain/Signal Enhancement (as required, may include) \\ Radon Multiple Attenuation \\ Spectral Balance \\ Noise Attenuation \\ Amplitude Balance \\ Interpolate final volumes to $110 \times 110$ bin
}

\section{John H. Virginia University Libraries, ou=Acquisitions Department,

